\title{
Report on the Gaithersburg NanoNuclear Workshop and Strategic Planning Recommendations
}

Steven J. Winston

Robert Price

Mike Cappiello

Bill Weber

Jim Buelt

Tina Nenoff

Stuart Maloy

Jim Sears

September 2012

The INL is a U.S. Department of Energy National Laboratory operated by Battelle Energy Alliance

Idaho National Laboratory 
INL/EXT-12-27297

\title{
Report on the Gaithersburg NanoNuclear Workshop and Strategic Planning Recommendations
}

\author{
Steven J. Winston \\ Robert Price \\ Mike Cappiello \\ Bill Weber \\ Jim Buelt \\ Tina Nenoff \\ Stuart Maloy \\ Jim Sears
}

September 2012

\begin{abstract}
Idaho National Laboratory Idaho Falls, Idaho 83415
\end{abstract}

http://www.inl.gov

Prepared for the

U.S. Department of Energy

Office of Nuclear Energy

Under DOE Idaho Operations Office

Contract DE-AC07-05ID14517 


\section{Report on the Gaithersburg NanoNuclear Workshop and Strategic Planning Recommendations}

Steven J. Winston Editor/Author Robert Price Editor/Author Mike Cappiello, Bill Weber Physics-TH Breakoy Session CoChair/Author Jim Buelt, Tina Nenoff Separations Breal Stuart Maloy, Jim Sears Mechanical Pakout Session Co-Chair/ Author

BEA Contract \# 123017 


\section{Table of Contents}

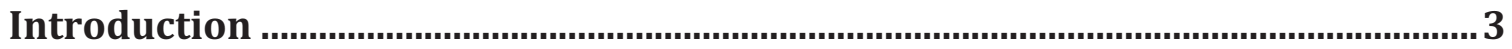

I. Physics, Fuels and Thermal Hydraulics ...................................................... 6

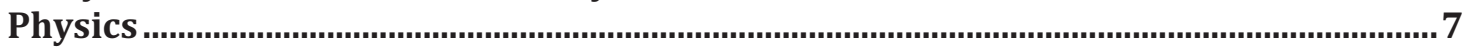

Application of Nano-Technologies........................................................................................

Recommended Future Research..............................................................................................

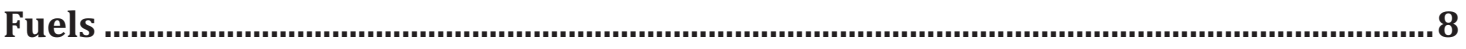

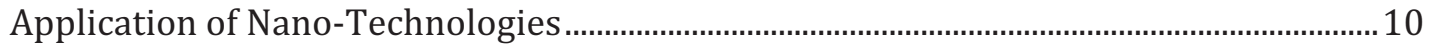

Capability and Facility Needs................................................................................................ 11

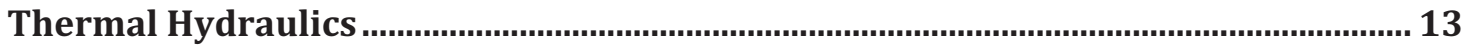

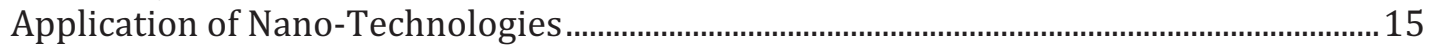

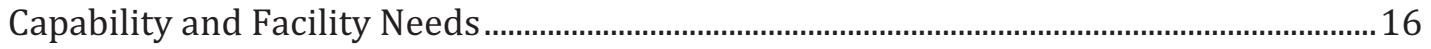

Recommended Future Research.......................................................................................

II. Chemical Properties and Separations................................................................ 18

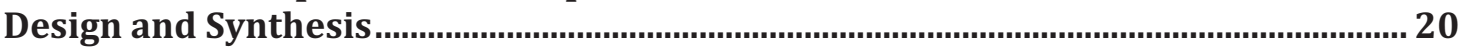

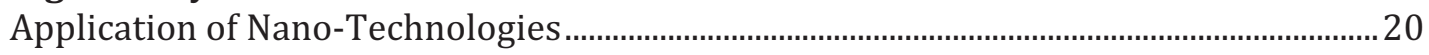

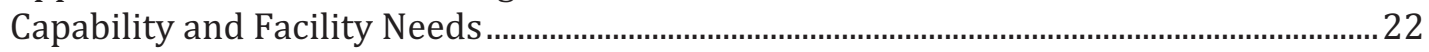

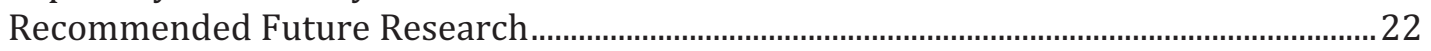

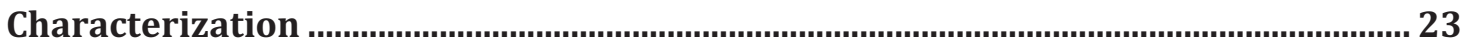

Chemical Interaction and Separation Methods Development....................................... 25

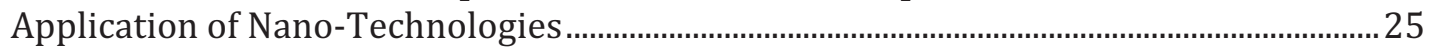

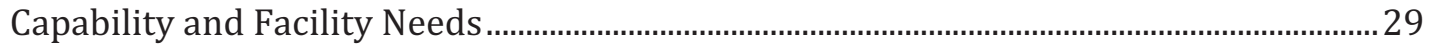

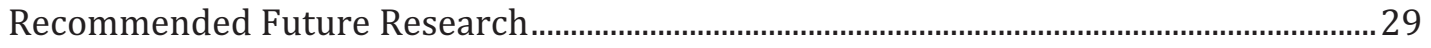

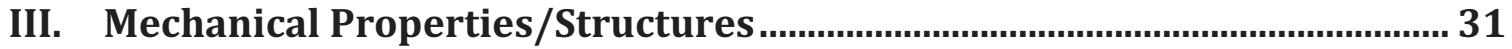

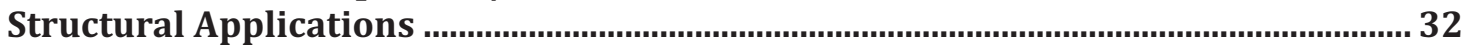

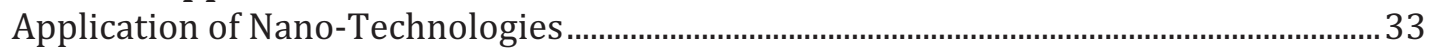

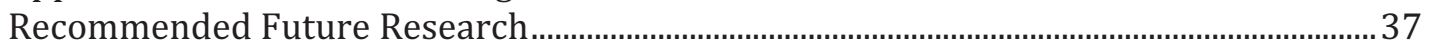

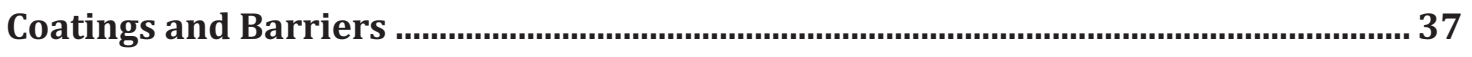

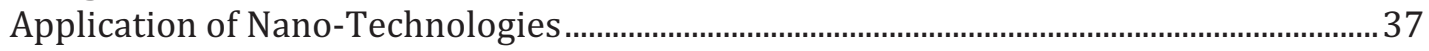

Coolant Piping Applications.................................................................................................. 38

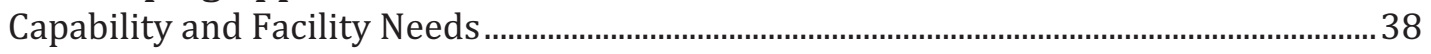

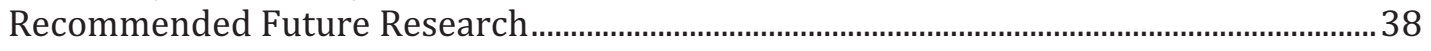

Nano-layered/Strengthened Composite/Hybrid Materials ........................................ 38

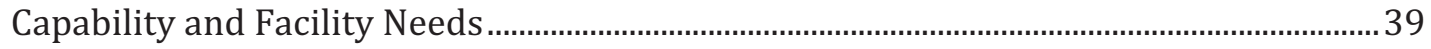

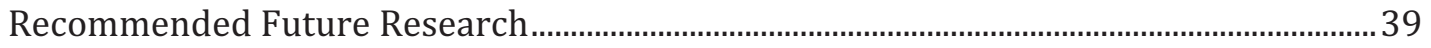

In-Core Reactor Applications ............................................................................................ 39

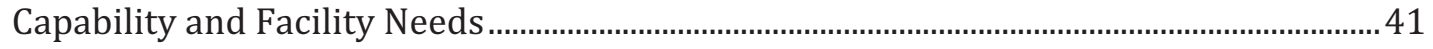

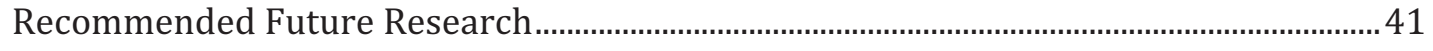

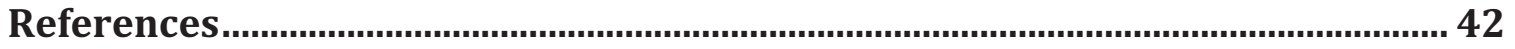




\section{Introduction}

From inception as a delightful curiosity of novel geometries beginning in 1985, nanoscience has already revolutionized huge expanses of high technology (e.g., electronics and medicine) with amazing advances previously thought to be beyond credulity. Nuclear energy, as a large domestic source of clean, nearly greenhouse gas-free energy, is making major contributions toward meeting our nation's current and future energy demands. However, it faces a myriad of challenges that could prevent it from realizing its full potential to help us meet our economic, environmental and energy security goals. Nuclear energy might greatly benefit from adaptations of nanoscale methods and materials in order to overcome these challenges and achieve a continued or an expanded role in our long-term energy platform.

Potential applications of nanotechnologies can be envisioned in a wide variety of nuclear energy technical areas, for example, structural materials, coolants, fuels, components, detectors, instrumentation, separations processes, and waste forms. However, currently little is known about the effects of the rigors of a nuclear environment (e.g., high radiation fields, temperatures, pressures) on nanomaterials. Research and development is needed, which must be informed by a deeper understanding of what is plausible, what is not, and what are the potential benefits and R\&D needs.

On 6-8 June 2012 a meeting was held in Gaithersburg, MD in order to bring together representatives from the nuclear energy and nanoscience communities to evaluate the potential for nuclear energy to benefit from nanotechnology; over 120 experts from academia, DOE national laboratories, and other federal agencies attended.

Panels were formed to address this potential in three areas: physical/thermohydraulic properties, chemical properties, and mechanical properties. Each panel was charged to answer three questions:

- What are the potential benefits from the use of nanoscience in nuclear energy?

- Is focused R\&D on nanotechnology related to nuclear applications warranted, and if so what R\&D should be conducted?

- What facility and/or capability needs are needed?

Each of the panels identified significant potential breakthroughs and benefits that may be achievable through the use of nanotechnologies in nuclear energy applications. Examples include:

- Sensors for: radiation, temperature, pressure, stress/strain, or even chemistry; or in situ diagnostics of material properties and mechanical response; with significantly reduced size and weight and increased sensitivity, performance, and functionality that could provide enhanced, near real time sensing of the reactor plant or reprocessing plant component or 
system conditions. This could have significant benefits operating the reactor with increased safety margins because in many cases, these measurements are currently not able to be performed because of the extreme reactor conditions.

- Detectors that can discriminate between neutron and gamma radiation and enhanced detection of fissile materials with very low neutron activation fluxes, which could provide benefits in safeguards and security applications.

- Fuels with increased fission gas retention, plasticity, radiation tolerance, heat transfer capability, strength, and/or reduced Fuel Cladding Chemical and Mechanical Interactions thereby achieving longer service lives and reducing the potential for failure.

- Fuel fabrication methods that reduce process losses.

- Nano-fluid coolants and/or nano-engineered surfaces that significantly enhance heat transfer properties of fuels to increase accident tolerance or reduce size and cost of steam generators.

- Improved separation of fission products and/or fissionable material from recycling operations that could reduce processing wastes requiring geologic disposal and enable new mining or environmental remediation techniques.

- Chemical interaction and separation methods using nanoparticles and/or nanoporous materials that can enable techniques to capture fission product gases either from reprocessing operations or directly within a reactor fuel assembly thereby reducing the potential for releases from normal or accident conditions.

- The use of nanoparticles and/or nanoporous materials that can enable the economic separation of uranium from seawater thereby unlocking a nearly limitless supply of nuclear fuel as well as new methods to extract strategically-important rare earths directly from soils.

- Structural materials where nano-sized precipitates could improve mechanical performance as well as irradiation tolerance by acting as sinks for radiation-induced defects. Higher performance materials could lead to reduced construction costs, increased operating efficiencies, and improved performance in accident conditions.

- Nanostructured barriers and coatings that could improve corrosion resistance and surface hardening with application to fuel claddings, piping, and heat exchangers. The potential is to improve performance in normal and accident conditions and potentially eliminate the need for large component replacements, e.g. steam generators.

- Composite/hybrid materials with significant improvement to concrete structures for application in the nuclear industry. For example, graphene oxide or boron nitride nanotubes added as powders to concrete could possibly improve strength and toughness and could lead to reduced concrete cracking issues.

- Composites with higher thermal conductivity could be used in advanced heat exchanger applications. 
Based on the above, each of the panels believed that focused R\&D is needed to evaluate the potential for nanotechnologies to survive the rigors of the nuclear energy environment and to develop the potential for these technologies. Some high priority R\&D needs include:

In the physical/thermo-hydraulic area, specific research is recommended in:

- determining the survivability of nano-structures like fullerenes in the conditions found within nuclear fuels and how to use nano-structures and properties to enhance fuel performance and accident-tolerance.

- developing nano-scale sensors and detectors for use in reactor fuels, components, systems and for use in safeguards and security applications.

- the application of nano-fluids and nano-engineered surfaces to enhance heat transfer.

In the chemical area, specific research studies are recommended in:

- surface passivation,

- surface functionalization,

- characterization methods,

- stimuli-based processes, and

- uranyl nanoclusters.

In the mechanical area, specific research is recommended for:

- development of nano-strengthened ferritic alloys along with related joining techniques and fabrication techniques;

- the development of coating techniques for applying nanomaterials to cladding tubes or coolant piping along with the testing of the barriers and coatings under prototypic reactor conditions to insure their integrity;

- defining the mechanical properties of concrete reinforced with nanomaterials;

- development of techniques for producing heat exchangers using BN-NT reinforced fabrics and test thermal performance of these composite materials; and

- development and testing in-situ sensors under prototypic reactor operating conditions and determine their lifetime under operating and accident conditions.

To enable research into nanonuclear materials and phenomena, a combination of capabilities are required, including: radiological labs and characterization equipment, irradiation facilities (including gamma and neutron sources, UV-vis lamps, proton accelerators, high energy X-ray beams), crystallographic instruments (e.g., single crystal X-ray, SAXS, high resolution TEM with elemental analysis capabilities), , and instruments to detect nanoparticle formation detection (e.g., UVvis). 
While a significant number of facilities have some of these capabilities including many national lab facilities and universities few are set up to handle radioactive materials in these instruments. For example, significant nano-science capabilities and facilities exist in the United States, particularly at the five Office of Science funded nano-science centers at Argonne National Laboratory, Brookhaven National Laboratory, Lawrence Berkeley National Laboratory, Oak Ridge National Laboratory, and the center jointly administered by Los Alamos and Sandia National Laboratories. However, none of these facilities has the capability to handle radiological materials.

An issue that requires addressing is the apparent lack of consensus safety standards related to working with radioactive nano-materials.

In general, nanomaterials applications to the nuclear industry will require significant testing coordinated with materials development to qualify new materials for service. These efforts would be greatly improved through the development of physics-based models to help realize the benefits of these applications at the nanoscale. Through the development of models that capture processes at the atomic scale, materials can be tailored to the specific nuclear application and eventually these models can be used to predict lifetimes under extreme nuclear reactor environments.

\section{Summary Observations and Recommendations}

1. The application of nano-science has the potential for profound advances in nuclear energy technologies.

2. To achieve these potential breakthroughs funding to conduct specific research and development in nano-nuclear materials and phenomena should be provided. 3. Facilities and capabilities that allow for nano-scale radiological materials to be investigated are needed. New facilities, upgrades to existing facilities, or arrangements to partner nano-science centers with radiological facilities are needed.

4. ES\&H standards to specifically address the potential hazards associated with nano-scale radiological materials may be needed.

\section{Physics, Fuels and Thermal Hydraulics}

This breakout session examined the nanotechnologies with potential for enhancements in the areas of physics, fuels, and thermal hydraulics. There was a general consensus among the participants that nano-technologies can enhance the efficiency of existing reactors and provide for greater accident tolerance. The most promising areas of research that could have a high pay off in the near term include nano-engineered surfaces, nano-fluids and advanced fuels engineered and 
fabricated with nano-technologies. In addition it was recognized that nanotechnologies could be used to increase the efficiency and reduce the size and weight of radiation sensors, which may provide a major benefit to non-proliferation activities.

Funded research needs coordination in the area of the fuel-clad-coolant system. The materials effort to bring us new robust cladding materials needs close coordination with the fuels effort because of their obvious interactions and needs for compatibility. In addition the efforts on the nano-fluids and engineered surfaces need to provide solutions that are compatible with the operating environment and any new cladding materials or protective nanolayers that are developed as a result of these research efforts.

The next step in the development will bring the most-promising nano-nuclear technology to reactor applications and eventually commercialization. In this area, some capability gaps do exist, particularly in the area of thermal hydraulics. Demonstration facilities in the US that once were devoted to understanding the thermal hydraulics of rod bundles in steady state and under accident conditions have been shutdown. Some of these facilities were funded by industry and others by the USNRC research branch. With the computational power of current-day super computers, attendant theoretical models and large-scale 3-dimensional performance codes, it may be possible to avoid rebuilding some of these capabilities; however, some testing capability must exist to validate materials performance for licensing.

Finally, it is recognized that it is important to continue research in the basic sciences to develop the scientific underpinnings and materials advances of nano-technology. Nonetheless, it is equally important that researchers are aware of the real world challenges, particularly those facing the nuclear industry. This conference has achieved a major milestone in bringing these communities together, and such opportunities for technical interaction should be continued.

\section{Physics}

This technical area includes the topics of shielding and sensors. There is a wide range of applications for shielding materials in practice these days. Shielding of course is necessary to protect workers in nuclear plants and first responders in the event of nuclear disasters (e.g., terrorist attack). It also is used in hospitals, cancer treatment centers, research centers, dentist offices, and in space applications just to name a few. The use of nano-materials will not affect neutron or high-energy photon interactions with the material, as these interactions occur at the nucleus scale and are for the most part irrespective of the crystal structure. For bulk shielding that is required in reactor and waste stream applications, high-density materials such as lead, concrete, and iron are the materials of choice. The introduction of nano-materials will not change the shielding performance, but it is possible that they can help maintain or enhance the mechanical performance. For 
certain neutron shielding applications, multi layered systems (to introduce light and heavy materials) are an area where nano-materials may provide a benefit.

Nanotechnology provides the potential to fabricate new functional materials and devices by taking advantage of novel properties and quantum phenomena (Kalantar-Zadeh \& Fry, 2007), which could have a significant effect on sensors. There are a wide range of potential applications for nanotechnology enabled sensors in research and testing, as well as in the nuclear industry, including sensors for radiation, temperature, pressure, and in situ diagnostics of material properties and mechanical response, just to name a few. The use of nano-technology in this area will potentially minimize the size and weight of sensors and increase sensitivity, performance and functionality.

\section{Application of Nano-Technologies}

With respect to sensors, nano-structured materials can possibly be used for neutron and gamma discrimination. Maintaining nano size can enable non-cubic systems in polycrystalline formats. This avoids the use of single crystals, which are very expensive. In addition, it may be possible to manage the grain size so that the material is optically transparent.

Boron carbide neutron detectors are being developed using semiconducting polymers. Potentially these detectors will provide for enhanced fissile material detection at with very low neutron activation fluxes. It has been found that $\mathrm{B} 5 \mathrm{C} / \mathrm{SiC}$ hetero-junctions are highly radiation resistant.

\section{Recommended Future Research}

In the important area of non-proliferation, extremely sensitive sensors are required to recognize and discriminate covert material transport. Deploying small, lightweight, inexpensive sensors in this area could have a major impact in protecting the public from terrorist activities and should be a fertile area of research.

\section{Fuels}

In this breakout session, the major parts of the discussions were related to the areas of nuclear fuels for commercial reactors, nuclear fuels for advanced reactors, and nuclear fuels for research reactors. The fuel used in commercial nuclear reactors is predominately a ceramic cylindrical pellet made of uranium dioxide $\left(\mathrm{UO}_{2}\right)$ or in the case of mixed oxide fuel (MOX) uranium-plutonium oxide. In advanced fast reactors, this fuel may be made of uranium, uranium-plutonium, or uranium-transuranics in the form of metals, oxide, nitrides, carbides or dispersions. For low enrichment 
replacement fuel in research and test reactors, the fuel is usually in the form of plates with various uranium ceramics used as the fuel material.

Commercial nuclear power plants dominate the reactors deployed today, and therefore are of great interest when it comes to performance and safety. The fuel used must be highly robust, high quality and easy to fabricate. Uranium dioxide was chosen as the fuel of choice because of its stability at high temperature, relative ease of manufacture, compatibility with the coolant (in the case of cladding breach), and other features. Current ceramic fuels, such as $\mathrm{UO}_{2}$, have a high melting point but suffer from low thermal conductivity, the preponderance to crack during irradiation (see figure 1 below), a high oxidation rate in the presence of steam, and the high release of fission gas. It is the continual desire of the nuclear power community to increase the steady state efficiency, lifetime and robustness of the fuel/clad system. In addition, in the aftermath of the nuclear meltdowns and hydrogen explosions at the Fukushima Daichi plants, there has been an increased emphasis on increasing the accident tolerance of commercial reactor nuclear fuels. Many improvements are needed in the cladding where the zirconium oxidation problem and hydrogen production is of great concern. Because a parallel session dealt with the cladding and this safety issue, this session focused on the fuel pellets, the "meat" of the fuel pin. With respect to the pellets, some of the stated goals for nano-technology include:

- Mechanically "soft" fuel to eliminate or reduce Fuel Cladding Mechanical Interactions (FCMI)

- Chemically inert fuel to eliminate Fuel Cladding Chemical Interactions (FCCI).

- Enhanced retention of gaseous fission products to reduce end of life pressure and help extend fuel pin lifetime.

- Enhanced retention of solid and liquid fission products to help lower the source term during accidents.

- Low loss processing including net shape pellet fuels to minimize waste during manufacture.

- Advanced synthesis, sintering and fabrication techniques to reduce manufacturing costs and improve quality.

- Higher conductivity, while maintaining a high melting temperature $\mathrm{UO}_{2}$ melts at $2750^{\circ} \mathrm{C}$ but suffers from low conductivity). Higher conductivity means a lower operating temperature and lower stored energy in the fuel, which improves safety during certain accident scenarios.

- Improved reaction kinetics with steam including lower heat of oxidation, and lower oxidation rate. In the case of cladding rupture this would lower the source term.

For commercial reactors there is a huge potential payoff to increase the thermal conductivity in the radial direction, improve fission gas and fission product retention, and reduce the cladding mechanical interaction, as all of these 
performance enhancements lead to higher efficiency, lower cost, longer life and larger safety margins.

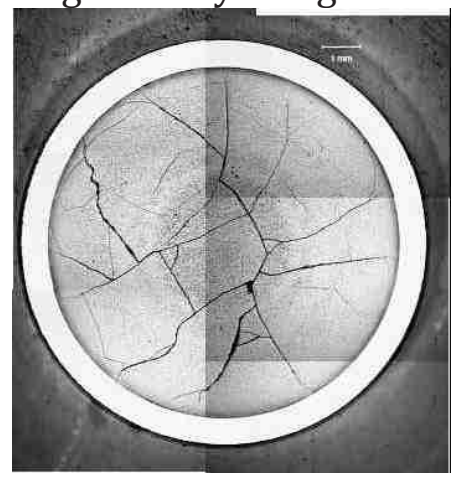

Fig. 1 Cracking Behavior of Irradiated $\mathrm{UO}_{2}$

In advanced fast reactors, both ceramic and metal fuels have been used with varying degrees of success. Many of the goals of the commercial reactors given above also apply here. In addition, there is a much more severe radiation damage environment to contend with, and very high fuel lifetime requirements. Fabrication is complicated because of the significant loading of plutonium and the higher actinides required for transmutation fuels. This is especially true for the ceramic fuels where the high sintering temperatures cause loss of the more volatile actinides. Metal fuels have the advantage of a high density and conductivity, which are useful attributes for fast spectrum reactors. Issues for metal fuels include low melting point $\left(1035^{\circ} \mathrm{C}\right)$, and fission product (lanthanide) transport to the clad inner surface, which can cause FCCI. In addition developing a commercially viable low waste fabrication method is needed.

With respect to research and test reactors, The Reduced Enrichment for Research and Test Reactors (RERTR) Program within the DOE/NNSA is developing technologies necessary to enable the conversion of civilian facilities using highenriched uranium (HEU) to low enriched uranium (LEU) fuels. To replace HEU fuel with LEU and maintain an equivalent reactor performance requires an equivalent atomic density of U-235, and therefore a much higher overall fuel density. Typical fuels are made of $\mathrm{U}_{3} \mathrm{Si}_{2}$ enclosed in an aluminum plate. Fuel densities approximately double that of $\mathrm{U}_{3} \mathrm{Si}_{2}$ is one of the goals of the program. A similar issue is with the production of LEU targets for Mo-99 production.

\section{Application of Nano-Technologies}

It is recognized that nano-materials like fullerenes may play a role in achieving some of the goals listed above. A fullerene is a molecule composed entirely of carbon, in the form of a hollow sphere, ellipsoid or tube. Spherical fullerenes are also called buckyballs, and they resemble the balls used in soccer. Cylindrical ones are called carbon nanotubes or buckytubes. Fullerenes are similar in structure to graphite, which is composed of stacked graphene sheets of linked hexagonal rings; 
but they may also contain pentagonal (or sometimes heptagonal) rings. They exhibit very high conductivity (thermal and electric), and high directional strength. Bulk nanocrystalline oxide fuels are being investigated at the Institute for Transuranium Elements (ITU) for commercial light water reactors and burning of actinides (Spino, Santa Cruz, Jovani-Abril, Britcher, \& Ferrero, 2012). Such nanocrystalline fuels could lead to increased fission gas retention, plasticity and radiation tolerance; however, grain sizes may need to be kept above $100 \mathrm{~nm}$ to avoid deterioration of the thermal properties. Methods are needed to increase the thermal conductivity in the radial direction for both steady state and accident conditions. It may be possible to layer the uranium dioxide with conductive sheets of fullerenes, for example, or distribute carbon nanotubes in the structure. This would provide for an overall increase in conductivity and an attendant increase in heat transport thru the fuel thereby lowering the operating temperature. Another possibility is to manage mass transport properties (fission gas, oxygen, fission products) along grain boundaries and reduce the fracturing of the fuel. To address fuel pin lifetime, gettering and condensing fission gas within the plenum above the fuel stack would reduce the end of life internal pressure. Research in this area is just beginning at Brookhaven National Laboratory.

With respect to metal fuel manufacture, it may be possible to build fuel slugs using advanced synthesis techniques such as laser additive manufacturing. Or, nanocoatings could be applied to the molds used for heavy metal fuel casting to make them reusable. In addition, the use of expandable coatings on the fuel was proposed

as a possible method to reduce FCCI and FCMI. In this case, carbo-silenes can form a kind of "metal spandex" that can be applied to fuel pellets.

With respect to RERTR fuel, UMo in an aluminum matrix is one of the preferred fuel materials. With its high density (17 - $18 \mathrm{~g} / \mathrm{cm} 3)$, UMo alloys can overcome the performance degradation of the LEU. But using metallic fuel in a water-cooled reactor introduces challenges during accident conditions. Dispersion fuels and coated particles have been proposed. Coatings with alumina and ZrN are also proposed. There may be novel nano-fabrication techniques to apply to this problem.

\section{Capability and Facility Needs}

Rapidly exploring the potential of nanotechnology innovations to nuclear fuels, particularly effects on irradiation response and microstructure evolution, cannot be limited solely to in-reactor testing. While not without limitations, ion irradiation provides a potential means to fundamentally explore the response of nanostructured materials to irradiation environments over a wide range of conditions, without introducing significant radioactivity. It can also provide separate effects data for model development. Like neutron irradiation facilities, ion irradiation facilities are becoming increasingly scarce in the USA, and few, if any, can achieve the energies of fission products that drive irradiation damage and microstructure evolution in nuclear fuels. 
Any new fuel will eventually need to undergo rigorous in-reactor testing prior to commercialization. Because of this, accepted changes are usually incremental steps that are not far from the existing experience. To implement a major change requires advanced modeling and simulation coupled with out-of-reactor separate effects testing, in-reactor integral testing and in-reactor transient testing. Complementing the testing capability, high quality characterization and post-irradiation examination capabilities are required. Some of these capabilities exist in the US, but some do not, and some once existed and will need to be recovered.

\section{Recommended Future Research}

Buckyballs and buckytubes have been the subject of intense research, both for their unique chemistry and for their technological applications, especially in materials science, electronics, and nanotechnology. Formation of Uranium buckyballs formed with $\mathrm{U}, \mathrm{O}, \mathrm{H}$, has been demonstrated at Notre Dame thru the EFRC. This technology has obvious applications in actinide separations during reprocessing; however, whether such structures might prove useful to nuclear fuels, as in controlling the structure during fabrication or in novel fuel designs, is an area of needed research. Accurate, predictive models will help direct the research into high payoff areas. Research on using nano-technologies in fuel pins is only just beginning. Two examples of NEUP funded activities include work at the University of Florida on high thermal conductivity $\mathrm{UO}_{2}$ with carbon nano-tubes using spark plasma sintering and work at BNL on fission gas getters based on nano-tubes. It is recommended that these types of funded activities be increased.

The environment inside a $\mathrm{UO}_{2}$ fuel pellet is extreme. The very high operating temperature $\left(2000^{\circ} \mathrm{C}\right)$ in the presence of oxygen with intense radiation damage from fission product recoil, fission gas generation, intense fast and thermal neutrons and the attendant high energy gamma radiation will make it very difficult for fullerene structures such as nanotubes to maintain integrity. In addition, the covalent bonds in these structures may be very susceptible to radiation damage. This is also true for getters introduced into the plenum. To avoid the oxidizing environment of $\mathrm{UO}_{2}$, it was proposed that UN or UC fuels might offer advantages, especially with the introduction of carbon fullerenes. It was also suggested that a nano-phase that is attached to the grain boundaries in UN would enhance the performance. It is recommended that researchers perform separate effects testing to understand which nano-materials can best survive in the extreme environment in $\mathrm{UO}_{2}$. Research is also needed to explore other fuel types such as UN and UC.

With respect to fast reactor fuels, fullerenes can potentially be used to encapsulate volatile actinides (for example, Am) to reduce significantly the losses during fabrication. As mentioned above, fullerenes would be more compatible with a nitride or carbide based fuel rather than an oxide. 


\section{Thermal Hydraulics}

The subject of thermal hydraulics in this context is focused primarily on the improvement in the effective heat transfer from the fuel pin cladding to the coolant and improving the heat transfer in the other heat exchangers in reactor coolant and power generation system. Both steady state operation and accident conditions are equally important. It is proposed that the use of nano-fluids and/or nanoengineered surfaces in nuclear reactors can provide an increase in thermal hydraulic performance and thereby allow for increases in safety margins and power uprates. Specifically, dilute nanofluids and nanoengineered surfaces have shown significant enhancement in CHF and nanoengineered surfaces significant enhancement in quench rate (Buonginorno, Venerus, Prabhat, \& McKrell, 2009).

A nano-fluid is a fluid base, such as water, containing nanometer-sized particles, called nanoparticles that range in size from 1 to $100 \mathrm{~nm}$. These particles form colloidal suspensions within the base fluid and do not settle out (see figure 2 below). The nanoparticles used are typically made of metals, metal oxides, carbides, polymers, or carbon. Shapes can be spherical, non-spherical or even carbon nanotubes. Although higher volume fractions of particles are possible, it has been found that particle volume fractions of $0.1 \%$ or less facilitate the formation of stable suspensions that provide significant thermal hydraulic benefit without significantly increasing the viscosity (keeping pumping costs manageable). Additionally, at these loadings, accelerated erosion of surfaces has not been reported.

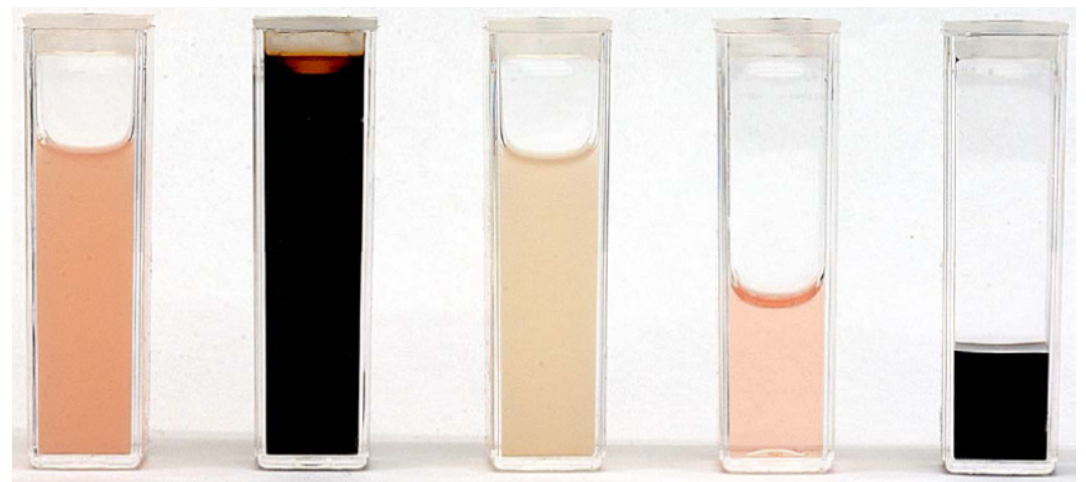

Fig. 2 Nano-fluids, Photo courtesy of Prof. A. Hatton (MIT)

Commercial nuclear power in the US is completely dominated by light water cooled reactors (LWRs). Of the 104 operating reactors, 35 are boiling water reactors (BWRs) and 69 are pressurized water reactors (PWRs). The power level that plants are allowed to operate at is determined by several limits, including analytical results of design basis accidents. One class of accidents includes loss of coolant and loss of heat sink. In these cases, the core may lose its coolant thru depressurization or boiling from loss of pumping power during station blackout, for instance. In either case, a maximum heat flux may be reached where the heat from the surface exceeds that which can be removed from the boiling liquid. This point is called the "critical 
heat flux" (CHF) of a boiling system as shown in figure 3 below. Beyond this point, vapor essentially insulates the bulk liquid from the hot surface. The surface temperature must therefore increase substantially above the bulk fluid temperature in order to transfer the heat. This situation must be avoided in reactors to avoid fuel pin damage and melting, which is what occurred during the Three Mile Island accident and the severe accident at Fukushima Daichi. Additionally, designs that rely on in vessel retention systems could benefit from the use of nano-fluids (Buongiorno, Hu, S., Hannink, Bao, \& Forrest, 2008).

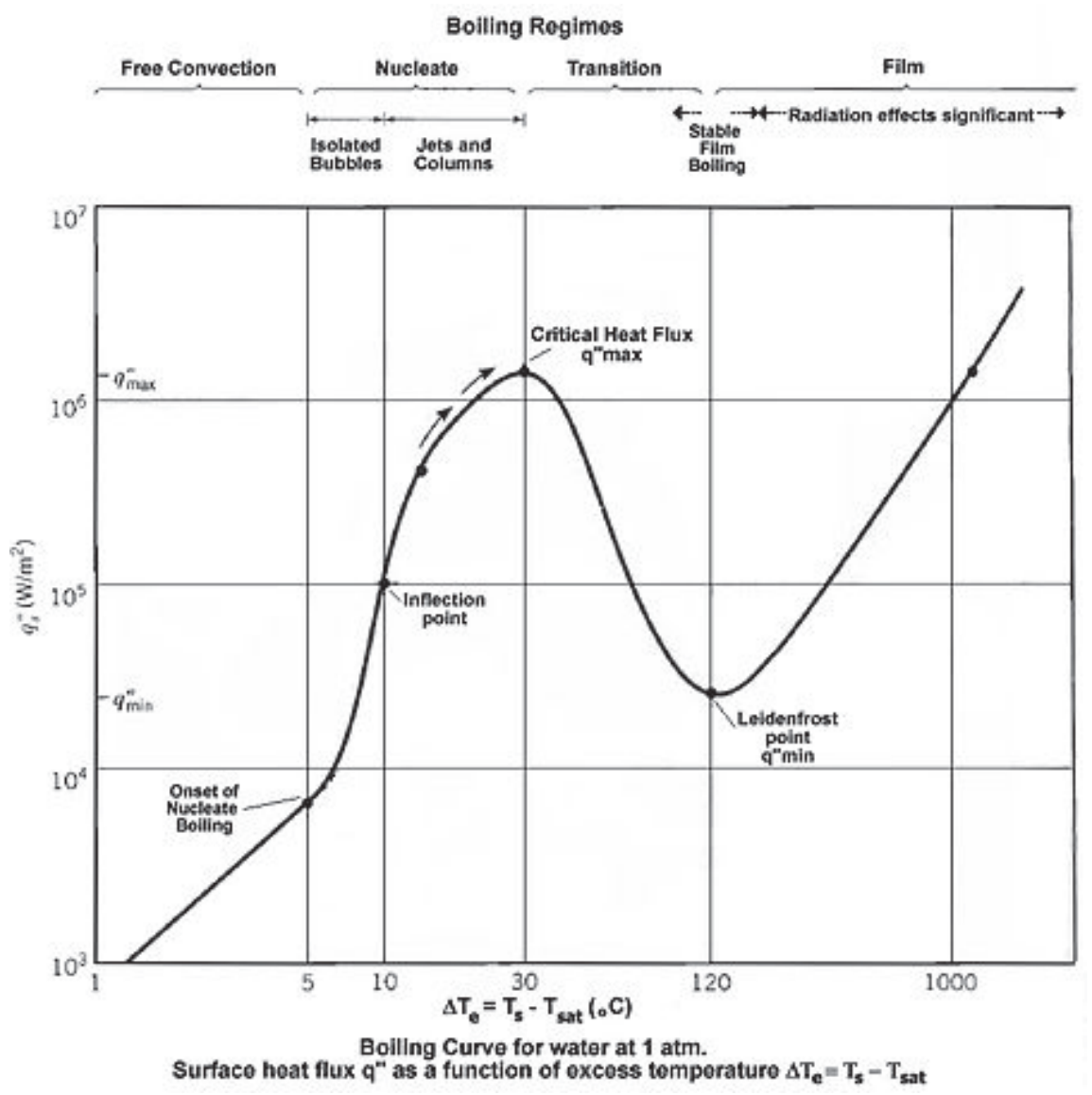

Fig. 3 Boiling Curve for water at 1 atmosphere pressure

In the operation of a nuclear plant the power of the core, and therefore the heat flux from the fuel pins is limited with a margin of safety to avoid departure from nucleate boiling (DNB) and critical heat flux (CHF). As discussed below, nano-fluids and/or nano-engineered surfaces have the potential to raise the CHF and therefore increase the margin of safety. Increasing margins will allow power uprates at plants. When applied to a large fleet of reactors the impact of small power uprates can be huge. For example, for the US fleet, a power uprate of only $1 \%$ would be equivalent to building a new nuclear power plant ( $\sim$ \$B cost) and offsetting 6.3 million tonne of carbon dioxide emissions per year (assuming replacement of 
equivalent amount of coal fired generation at $755 \mathrm{~g} / \mathrm{kWh} \mathrm{CO}_{2}$ ). Therefore this is a major opportunity where nano nuclear can make a difference.

Nuclear plants are designed with many safety systems that provide backup cooling and power to avoid damage to the plant and protect the public from the release of radioactivity. For instance, if a massive depressurization occurs and the core loses coolant, large water storage vessels are brought on line thru passively activated check valves to re-flood the core and re-establish cooling. The fuel pins (which are very hot at this point) undergo a quench. How fast the rods quench is again related to the boiling curve. As opposed to the case of dry out where one moves from left to right on the boiling curve, quench is the process of moving from right to left. In a vertically configured system such as a bundle of fuel rods, an important figure of merit is how fast the liquid can re-attach to the surface and "quench" the rods. To enhance safety one would endeavor to increase the "quench velocity". As discussed below, nano-engineered surfaces have shown the potential to increase the quench rate and therefore increase the margin of safety.

\section{Application of Nano-Technologies}

One method to enhance the heat transfer from a heated surface (i.e. fuel pin) to the coolant (i.e. water) is to raise the conductivity of the fluid. Small-scale experiments have shown that nano-fluids created with spherical particles can be used to enhance the conductivity, and therefore the single phase convective heat transfer. The experimental results are variable, but it is expected that existing theoretical correlations will hold, and nano-fluids will follow traditional heat transfer behavior and there will not be a huge enhancement for non-boiling applications without a viscosity/pumping power penalty (Buonginorno, Venerus, Prabhat, \& McKrell, 2009). Experiences with nano-fluids suggest that the amount of additive particles should be limited to small fraction of the coolant ( $\sim 0.1 \%$ by volume) to avoid increased viscosity and attendant pumping costs.

With respect to boiling heat transfer, experimenters have shown a 40-80\% increase in $\mathrm{CHF}$ at $1 \mathrm{~atm}$ pressure (0.1 MPa) and greatly enhanced quench rates in nanofluids compared to pure water (see figure 4). The key mechanism to these improvements involves establishing a very thin layer of nano particles on the surface with a certain amount of nanoporosity (Kim, McKrell, Buongiorno, \& L.W., 2009)It has been shown that a nanoporous hydrophilic 20 atom thick layer shows equal benefit to the 1-5 um layer formed during boiling in a nanofluids ( $\mathrm{O}^{\prime} H a n l e y$, 2012). It is postulated that the nanoporous layer destabilizes and pins the vapor film, and acts to pull water to the surface increasing the surface wettability. One method to apply this layer is to boil or quench the surface in the presence of an appropriate nanofluid. Preconditioning of the surface using this method may not be appropriate for fuel pins, so other methods should and are being developed. 


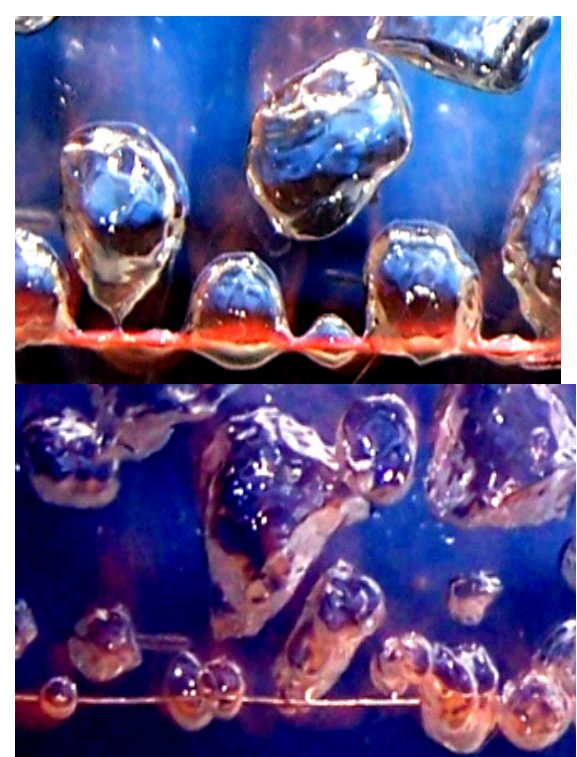

Fig. 4. Top Photo: De-ionized water at $1 \mathrm{MW} / \mathrm{m} 2$ heat flux (observe the vapor film coating the heated wire). Bottom photo: Nano fluid at $1 \mathrm{MW} / \mathrm{m} 2$ heat flux (fluid is still wetting the surface). (from Kim, S. J., 2007)

To be compatible with the commercial reactor conditions, the nano-particles and engineered surface layers must be able to withstand the high temperature and pressure environment $\left(315^{\circ} \mathrm{C}, 15.5 \mathrm{MPa}\right)$, and the intense radiation environment $\left(10^{13} \mathrm{n} / \mathrm{cm}^{2} / \mathrm{s}\right.$ neutron flux). In addition the particles must be compatible with other additives in the coolant that are used for reactivity control ( $\mathrm{LiOH}$, Boric Acid) and other corrosion control chemicals. Care must also be taken in choosing particles that do not upset or change reactor nuclear operation and safety parameters. Strong neutron absorbers should be avoided, for instance, as a loss of coolant accident would produce a reactivity insertion further exacerbating the event. Typical particle types include alumina, zirconia and diamond, all of which would have a minimal effect on reactor physics or safety parameters.

Another area that nano-engineered surfaces may impact commercial nuclear is in the steam generators. Increasing the heat transfer efficiency will allow for smaller heat exchangers, which in turn can reduce cost. Steam generators are a source of maintenance problems for many utilities, and often force operators to plug tubes and downrate their plant. Building a maintenance free compact steam generator would help reduce costs significantly.

\section{Capability and Facility Needs}

To implement nano-fluids in commercial nuclear reactors will ultimately require the approval of the US Nuclear Regulatory Commission. To prove their acceptance, a long series of testing will be required that starts with the very small scale and works up to full scale reactor tests. Some new test facilities supplemented by advanced modeling and simulation will be required. Demonstrating the use nano-fluids in an actual reactor is a bit more problematic as one cannot introduce a lead test 
assembly. Once nano-fluids are introduced into the reactor coolant, they are distributed across the entire core and primary coolant loop. Thus, prior to the acceptance of nano-fluids, there must be a very high degree of certainty that it will work as designed. To address this issue, separate effects tests will be required in scaled coolant loops that simulate realistic reactor steady state and accident conditions. (example: AP1000 thermal hydraulic test loop at Oregon State University). And finally, in reactor tests such as in an Advanced Test Reactor closed loop will necessary to demonstrate feasibility in a realistic combination of thermal hydraulic, chemical and radiation environment.

\section{Recommended Future Research}

Current research in the application of nano-fluids to nuclear energy in the US is being performed at Universities under grants from the Dept. of Energy. Globally over 100 groups and companies are involved in nano-fluid research. Initial smallscale tests are encouraging and warrant the continuation and expansion of this research in nanofluids and nanoengineered surfaces especially in the area of CHF improvement. At this point in the development the research is in the discovery and exploration stage and there exists a significant variability in the results. As research progresses it is recommended that some coordination be performed at the national level to help manage overlaps and ensure quality to help reduce variability.

Testing of nano-fluids and nano-engineered surface concepts at prototypic conditions will be necessary as the next step in the development process. There are insufficient data to draw conclusions on the stability of the nano-fluids and nanoengineered surfaces in realistic reactor conditions, and further studies, which include the role of contaminants in the coolant on fouling the surfaces, are needed. There is also the need for the development of theoretical models, and predictive capabilities to fully understand the mechanisms involved.

It is worth mentioning that developing a cladding material that does not oxidize at high temperature and does not produce hydrogen (as is the case with Zircalloy) is a goal of producing a more accident tolerant fuel/clad system. It is also compatible with this goal to develop an engineered surface coating that has much better CHF and quench characteristics. In fact it may be possible to produce a very robust coating that does both. This is a major opportunity for the nanonuclear community to make a difference.

\section{Summary}

In this breakout session the main emphases were on fuels, the clad surface, and the coolant. It was recognized that the fuel, clad and coolant form a system that must be addressed together because of the very strong interdependencies. For instance, what is proposed for fuel enhancement or coolant enhancement may not be compatible with what the materials scientists recommend for cladding 
improvements. Going forward, there must be a strong coordination with the materials cladding researchers and the fuel and coolant researchers. Developing joint goals for an optimum fuel-clad-coolant system would help this endeavor.

It was the general concurrence of the participants that DOE-NE should invest in this technology. The areas that have the highest potential for success in the near term are nanofluids and nanoengineered surfaces. Improvements in fuels also have a potential for success and offer a great opportunity. To realize their full potential will require a long-term research commitment.

For $\mathrm{UO}_{2}$ fuels it is recognized that to maintain the integrity of nano materials in the high temperature, oxygen rich, high radiation environment is a difficult challenge. There may be methods to overcome this hurdle, but testing in prototypic conditions will be necessary to discover which materials will survive.

Likewise for similar reasons testing of nano-fluids and surface treatments in prototypical coolant conditions is also needed.

\section{Chemical Properties and Separations}

As background for this session, the technical gaps associated with recycling used nuclear fuel identified by DOE-NE's Separations and Waste Forms campaign that may be addressed by nanotechnology are described as follows:

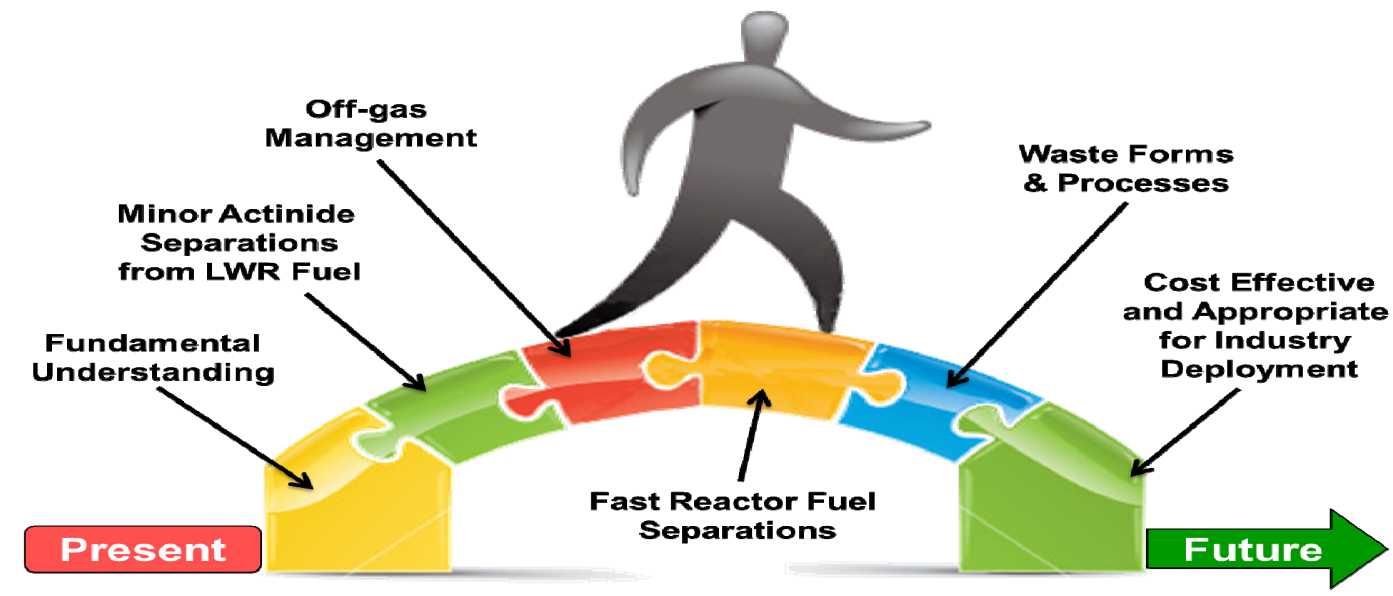

Full recycle technology gaps as defined by DOE's Separations and Waste Forms Campaign - J Vienna and T Todd, Presented to Used Fuel Disposition Campaign Meeting May 15-17, 2012

- Minor actinide separations from light water reactor fuel - minor actinides, such as neptunium, americium, and curium, have similar chemical properties to lanthanide series fission products and thus present unique separation challenges;

- Off gas management - recycling of spent fuel results in the release of gaseous and volatile fission products such as $\mathrm{Kr}-85$ and I-129 that present emission control challenges; 
- Fast reactor fuel separations - development of more effective processes to minimize losses in molten salt and aqueous separations processes will reduce waste management impacts

- Waste forms and processes - development of engineered waste forms that improve the certainty of stability in disposal environments for geologic time periods will assure confidence and expand disposal options

- Cost effectiveness for industry deployment - advanced nanotechnology processes must be attractive to industry

In addition, the desire to develop more effective and economic means of separating uranium as a fuel resource from seawater and low grade ores was discussed as well as developing in-core chemical methods, especially within the nuclear fuel plenum, to capture fission gases and prevent corrosion. Each of these challenges offers excellent opportunities to develop nanotechnology methods that can address these needs.

The session established an objective statement as follows:

"Formulate the basis for a sustainable research and development program for the development of nanotechnology that has the potential to substantially improve nuclear systems that involve chemistry, separations, and waste forms."

The general technical focus of the separations section of this workshop was on the chem- and physi-sorption of radiological entities found in, or pertaining to, the nuclear fuel cycle. The separation methods considered were far reaching and were narrowed down to physical separations by nanoparticles via surface agglomeration, nucleation, and/or precipitation, and by nanoporous materials by chemisorption processes. Because of the complexity of any separations in a nuclear arena and on the nanoscale, a multidisciplinary effort proved a recurring theme in this session, with a particular focus on the need to understand the structure-property relationships of nanoscale materials and how these influence the related bulk scale properties in separation processes.

To that end, a high value was placed on the integration of materials synthesis and testing with modeling/simulation and the necessary unique characterization techniques useful to both nuclear and nano materials. In particular, the ability to tune in high selectivity, high product yield, and purity is important in the world of nuclear separations, due to the need to keep radioisotopes, with differing half-lives and radiation doses, separate for storage and/or reuse.

The results of the two day session resulted in the categorization of three topical research and development areas involving chemical properties, as follows:

- Design and synthesis of nanoparticles and nanoporous materials 
- Characterization of the properties and behavior of nanomaterials, especially in radiation and extreme environments

- Chemical interaction and separation methods development using nanoparticles and/or nanoporous materials

The following sections describe the research thrusts for each of the topical areas.

\section{Design and Synthesis}

This technical area includes the research to design and synthesize both 1) nanoparticles that might be used in an aqueous, molten salt or molten metal environment to conduct chemistry and 2) nanoporous materials that may be functionalized to enhance the effectiveness of separations processes.

\section{Application of Nano-Technologies}

Fuel design for fission product release. Use of gamma irradiation for nanoparticle formation at room temperature allows for unique chemical compositions of the nanoparticles for future new fuels; sintering of nanoparticles allows for much lower sintering temperatures to form bulk vs. traditional melting methods, thereby ensuring no loss of radiological materials during compaction (eg., $\mathrm{Am}, \mathrm{mp} \approx 966^{\circ} \mathrm{C}$ ) and enabling unique fuel compositions.

Separation of Fission Products and/or Fissionable Material. The recycling and reuse of uranyl salt solutions produced from the acid dissolution of spent nuclear fuels is of particular interest for the reprocessing of nuclear fuels. The ability to utilize these dissolved salts as precursors for bulk $\mathrm{UO}_{2}$-based recycled fuels defines a materials pathway for the reduction of nuclear waste destined for long-term repository storage. Judicious design of the synthetic method of the nanoparticles from solution will aid in the composition of the final product (of value for the ultimate reuse). (Nenoff, et al., 2011) (Leung, 2012)

Another example is the ongoing research into the formation of uranyl nanoclusters via mild solution chemistry (Burns, Ewing, \& Nayrotsky, 2012). With the addition of peroxide and various charge balancing cations to a solution of uranyl ions, the result is the crystallization of a large number of novel uranyl nanoclusters (eg., $\left(U_{24}-U_{60}\right)$. They have been studied for the fundamental structure-property relationships as these nanoparticles form at low temperatures, and have interesting and mobile transport properties in geologic fluids. Of interest for the nuclear fuel cycle is whether their ease of formation and large nanoparticle crystal size range may make this type of nanoparticle formation useful for both uranium capture from solutions and/or a method for capturing uranium for reuse. 

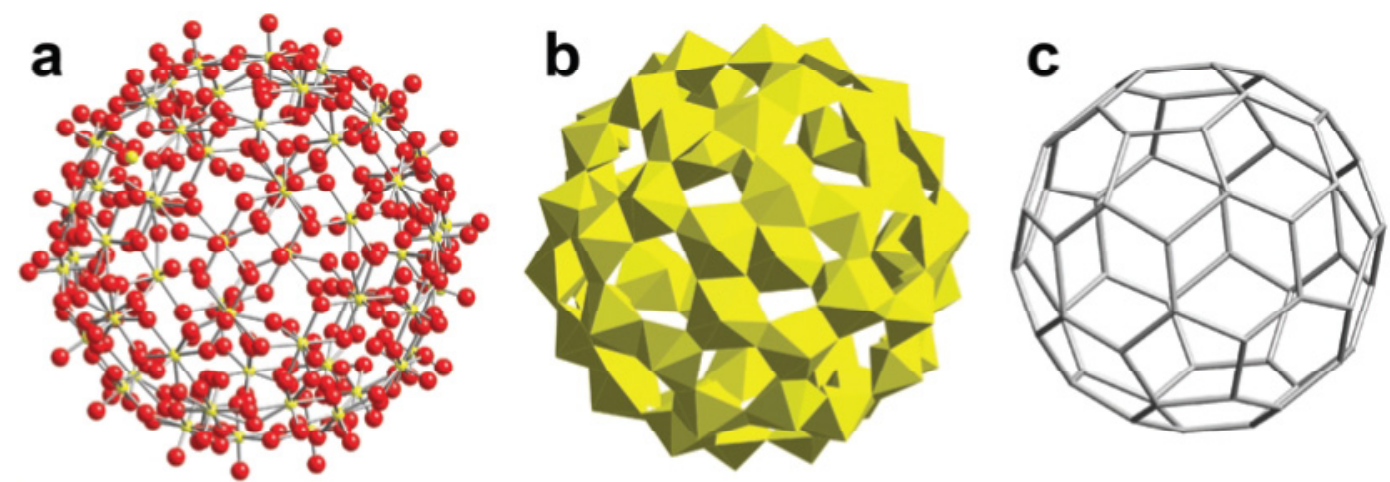

The nanoscale U60 cage cluster in ball-and-stick (a), polyhedral (b), and graphical (c) representations from Burns, P.C. "Nanoscale Uranium Based Cage Clusters Inspired by Uranium Mineralogy" Mineralogical Magazine, February 2011, Vol 75 (1), pp 1-25.

Research into nanoparticle phosphors may be leveraged to nuclear applications. Thermal decomposition routes of rare earth organometallics into nanoparticle oxides indicates that this may be one method of separation and capture of rare earths from soils, etc. (Si, Dr., Prof., \& Dr., 2005)

Monosodium titanate (MST) represents another material with nanoscale properties (Elvington, Tosten, Taylor-Pashow, \& Hobbs, 2012) that have been successful in removing Sr-90 as well as alpha emitters from the high level waste tank supernate at the Savannah River Site. High resolution transmission electron microscopy (HRTEM) of MST indicated that the material consists of an inner, micron-size, amorphous core and outer nanosize fibrous region (see Figs below). Energy dispersive analysis (EDS) indicated that the uptake of strontium occurs in the nanofibrous region without any change in the particle morphology. Furthermore, selected area electron diffraction (SAED) patterns did not change after exchange of strontium suggesting that the exchanged strontium does not facilitate a conversion to a more crystalline material (MC, DB, DT, SD, Z, \& JP, 2004) Thus, researchers at the Savannah River National Laboratory conclude that the outstanding performance of MST in removing $\mathrm{Sr}, \mathrm{Pu}, \mathrm{Np}$ and $\mathrm{U}$ from nuclear waste solutions results from the unique combination of nanofibers for excellent mass transport and the micron size amorphous core for good filtration characteristics.
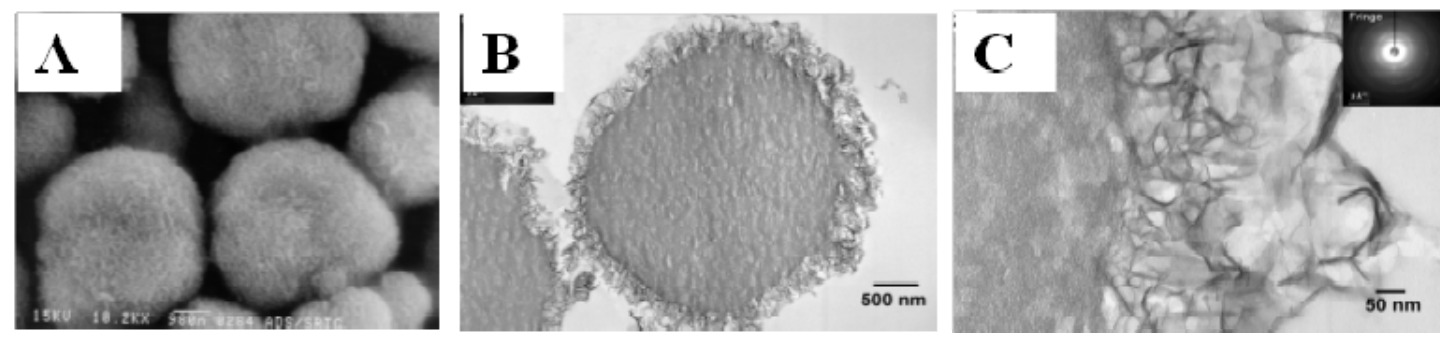

(A) SEM image of MST, (B) HR-TEM image of MST particle, (C) HR-TEM image and SAED of nanofibrous region of MST (Duff et al 2004)

Coatings for Corrosion Control. Nanoparticle coatings could be included on the exterior or the interior of fuel cladding to eliminate or control corrosion with the 
coolant on the cladding exterior and pellet-clad interactions on the cladding interior. For the cladding interior, these coatings could be considered to be a lubricant between the fuel meat and the cladding, reducing or eliminating abrasive effects. Development of such coatings needs to consider thermal transport effects (thermal conductivity of the interface) so that thermal conductance is not impaired and perhaps enhanced among other effects.

\section{Capability and Facility Needs}

Because of the combined hazards associated with radiological and nanoparticle chemical syntheses (radiological dose/contamination and high dispersibility, respectively), proper precautions need to be taken. Based on the size and composition of the nanoparticles synthesized, the following experimental set ups are suggested. They include radiological labs and characterization equipment, such as irradiation facilities (including gamma and neutron sources, UV-vis lamps, proton accelerators, high energy X-ray beams), crystallographic (single crystal X-ray, SAXS, high resolution TEM with elemental analysis capabilities (eg,. EDS, HAADF) and insitu TEM microfluidic studies of nanoparticle formation), and nanoparticle formation detection (UV-vis).

\section{Recommended Future Research}

Areas of recommended research include the following:

- Surface passivation -chemical or physical modification of the surface such that the material becomes less reactive under environmental conditions. Depending on the application, these environmental factors may include exposure to reactor coolant, reprocessing under molten salts and concentrated nitric acid solutions, and even contact with infiltrating groundwater. Nanoparticles could be deposited onto surfaces in very thin layers to either protect the material from corrosion or enhance the selectivity of removal of targeted chemicals by inhibiting reactions with competing media. Research in this field could make advances in the following areas, to name a few:

○ Smart getters to sorb only selected species while excluding water and other nontargeted molecules

○ Isotope selective hydrophilic nanoparticles for tritiated water separations

- Anti-agglomeration agents

- Improved resistance to chemical and thermal environments

- Surface functionalization - modification of nanoparticle and nanoporous surfaces with chemical groups that enhance their sorptive and reactive properties. Although functionalization of nanoscale materials has been studied and developed to some extent, this field of study offers tremendous 
potential for expansion with the variety of nanomaterials and functionalization agents available. Some examples of research topics in this field include:

- Nanoporous nanoparticles to increase surface area of nanomaterials allowing for improved functionalization and sorption capacity of the material

- Functionalized nanoporous substrates with selective extractants or sorbents such as calixarene.

- Self-healing materials - Grain boundaries and interfaces in solid materials are the sinks for defects such as vacancies and interstitials that lead to radiation tolerance and self-healing. Introduction of nanoparticles may help modify and strengthen these interfaces, which can introduce self-healing properties. This principle could be applied to all structural materials, including materials used for chemical interactions, capture, and separations, such as silica materials, small crystallites, etc. used in membranes and nanoporous support materials.

- Nanoparticle and Nanoporous Material Design - refers to the design and discovery of new nanoparticles with unique chemical and physical properties. This field of study can take advantage of chemical and physical property attributes associated with nanoparticle composition, their molecular morphology, and/or their surface attributes. Studies in the design and discovery of new nanoparticles could influence the following areas:

- Fuel design for preferential release of fission gases

- Porous aggregates of perovskites for fission product polishing

- Nanoparticles and nanoporous materials responsive to temperature, stress, radiation, or chemistry as sensor materials in nuclear fuel cores and fuel reprocessing

- Nanoparticle barcodes via neutron activation

Material design through modeling and simulation - refers to the use of advanced modeling and simulation methods to design nanoparticles and nanoporous materials. Modeling and simulation is critical to conducting screening of new nanomaterial designs to complement and synergize with experimental formulation methods. This approach would be necessary to reduce the experimental intensity of the program and focus experimental efforts on those materials that offer great promise or unique chemical/physical properties

\section{Characterization}

The combination of handling special nuclear materials including radiological samples as well as nanosize materials that have the potential to be easily released and transported into the workplace presents many challenges and requires a unique set of characterization techniques. However, with planning and coordination, these challenges can be overcome to provide the necessary characterization tools that to advance the understanding the structure-property relationships of nanomaterials with their respective applications. In addition, these techniques could be adapted for application in the field to conduct real-time monitoring of nanomaterial behavior 
through development of advanced sensors and software techniques to interpret their signals.

\section{Application of Nano-Technologies}

Characterization studies of nanoparticles and nanoporous materials will support the full complement of applications described in this Section. However, one particular application of characterization techniques can be applied to the field of sensors and on line monitoring. This application would adapt techniques used in the research laboratory for field application using field deployed sensors that take advantage of nanomaterial properties for real-time or near-real-time monitoring of the condition of the material or process fluid of interest. Nanomaterials could have a profound impact on the ability to sense the condition of a material or fluid. For example, incore nanoparticles that respond to temperature, stress, radiation, or chemical changes could then be subsequently interrogated for near real time sensing of the core condition. Another example is the use of nanomaterials to react to the chemical conditions of the medium in a reprocessing plant and then detect their change, perhaps through active interrogation mechanisms such as Raman spectroscopy.

\section{Capability and Facility Needs}

Nanoparticle and nanoporous materials can be fully utilized when their structure can be directly related to the materials' ability to perform separations through sorption, nucleation and/or precipitation; to detect process or material behavior in real time; or to passivate or activate surfaces. To that end, both small and large scale laboratories need to have equipment dedicated to various radiological levels, with hot cells for sample preparations and product characterizations. In the case that high dose fields will be required, user facilities across the country need to be readily available for use by smaller labs. It is important to note that currently in the US, there are 5 DOE/Office of Science nanotechnology user facility labs across the country; however, none are set up for the study of radiological materials).

Concurrently, special needs associated with nanoparticle product characterization should be established at laboratories, or at corresponding user facilities. Examples of this include drop-solution calorimetry for thermodynamic evaluation and comparison of nanoparticles (Armstrong, Nyman, Shvareva, Sigmon, Burns, \& Navrotsky, 2012), HRTEM facilities, and high energy X-ray facilities (eg., synchrotron source and Pair Distribution Function data collections at the Advanced Photon Source at ANL. Sample preparation will require access to hot cells that are suitable for nanomaterial studies. In addition, facilities for evaluating the performance of nanosensors under strong ionizing radiation and extreme environmental conditions, such as in hot cells or test reactor cores, will also need to be accessed. 


\section{Recommended Future Research}

Special equipment techniques - Characterization of novel nanoporous materials and nanoparticles will likely requirethe development of new examination and interrogation techniques. These techniques could be developed using advanced instrumentation already in use, such as X-ray microtomography, the National Synchrotron Light Source, nuclear magnetic resonance, differential and pairdistribution function analysis, and X-ray reflectivity. These techniques could be used to determine, for example:

- Preferential gas molecule siting locations in nanoporous materials

- Radiation damage assessment of nanomaterials and their substrates

- Behavior of legacy nanomaterials, such as the MSTs used in high-level defense tank wastes at DOE sites described in the previous section

- Fullerene effectiveness for separating minor actinides from lanthanides

- Ability of nanomaterials to prevent biofouling in marine environments for uranium extraction from seawater Modeling and simulation - As with the design of nanomaterials, modeling and simulation is critical to characterization and analysis of nanomaterials.

\section{Chemical Interaction and Separation Methods Development}

Safe nuclear energy is inevitably linked to the safe storage and disposal of nuclear waste. As such, extreme selectivity and durability are critical to materials used in nuclear separations and long-term waste storage. ${ }^{129} \mathrm{I}$ and ${ }^{85} \mathrm{Kr}$ are two of the radionuclides that remain of strong interest and concern. While these radionuclides are only found in small concentrations in nuclear effluents, their effective capture and storage is critically important to public safety. In addition, separation and capture of other isotopes such as H-3, Tc-99, Sr-90, Cs-137, Np-237, and Am-243, just as important in the safe and effective recycling of spent nuclear fuel.

\section{Application of Nano-Technologies}

Fission Gas Capture - Reprocessing: Less complex, more easily synthesized materials for fission gas separations and capture is of great interest with respect to scalability and manufacturing. Carbon materials, silica aerogels, and chalcogels are garnering much attention currently. The leading approach to capture radioactive, gaseous, fission byproducts during nuclear fuel reprocessing involves sorption onto aluminosilicate zeolites. Indeed, for many decades the silver-containing zeolite mordenite (MOR) has been a benchmark for radiological iodine capture; however, the molecular basis for its performance remained largely unexplored until recently. (Chapman, Chupas, \& Nenoff, 2012) Studies into the "how" and "why" this nanoporous material performed so well for nuclear related gas capture provided both answers for commercialization of 
the product and for general tuning and optimization of other nanoporous materials for fission gas needs.

This has led to the exploration of metal-organic frameworks (MOFs) for fission gas capture in reprocessing. The combination of advanced computing and synthesis/characterization with related gases have opened this avenue in nanoporous materials to nuclear applications. For example, studies of ZIF-8 (a MOF with small zeolite-like pore openings on the order of $\mathrm{I}_{2}$ gas molecule size) for Iodine gas showed the framework had structural durability for high weight loadings and high gas retention (lack of $\mathrm{I}_{2}$ desorption). (Sava, Chapman, Chaups, J.A., Crozer, \& Nenoff, 2011)Furthermore, recent studies have shown that mechanical pressure amorphizes the $\mathrm{I}_{2}$-ZIF-8 MOF to where the $\mathrm{I}_{2}$ remains captured but is held inside the material longer as compared to crystalline MOF, thereby making a one-step capture-interim storage material for the Iodine. (Chapman, Sava, Halder, Chupas, \& Nenoff, 2011).

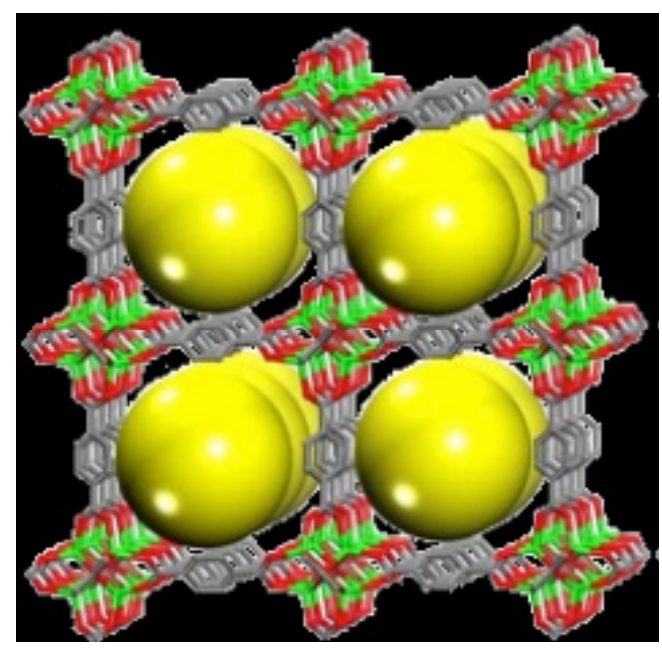

Isoreticular Metal Organic Frameworks for Gas Storage Applications (Eddaoudi, et al., 2002).

On-going large scale MOF structural data base screening is being employed by a number of groups for the downselecting of MOFs for selective separations of radiological gases (Van Heest, Teich-McGoldrick, Greathouse, Allendorf, \& Sholl, 2012). Concurrently, tuning of frameworks based upon predicted competitive sorption of various noble gases has led to successful separations studies of Xe/Kr by MOFs (Fernandez, Liu, Thallapally, \& Strachan, 2012) (Thallapally, Grate, \& Motkuri, 2012)

The ability to bring successful nanoporous material research from the chemical and petrochemical industries to nuclear fuel cycle applications may further succeed in the area of mixed-matrix membranes for increased gas permeability. For example, Janiek, et al, have successfully incorporated very large pored MOFs into polymer membranes for $\mathrm{O}_{2} / \mathrm{N}_{2}$ separations (Jeazet $\mathrm{H}$. , Tanh, Staudt, \& Janiak, 2012); extension to fission gases should be a logical next step. 
Fission Gas Capture - Fuel Plenum: One very interesting area of technological expansion may be into the development of nanoporous materials for fission gas capture in the nuclear reactor plenum. The plenum is the structural void/ area located above the bundled fuel rods. The ability to develop a mechanically, thermally and radiologically stable separations material that can withstand the radiological load so close to the rods is of great interest as a method to favorably remove fission gases as they are forming. One type of promising material are the titania ceramic nanoporous nanofibers being developed at Sandia National Labs (Bell, Liu, Garino, Rodriguez, Rademacher, \& Nenoff, 2012). Because of their crystallinity, mesolength scale nanoporous (interpore 5-10 nm, intrapore $100 \mathrm{~nm}$ ) and functionalization ability (zeolites, Ag nanoparticles), they are anticipated to be tunable and stable for plenum conditions.

Separation of Fission Products and/or Fissionable Material: Carbons for actinide and lanthanide sorption include nanotubes and fullerenes. Generally, activated carbon has been used for gas sorption, primarily due to its low cost and high relative weight loading capacity. However, the ability to tune new carbon materials makes it very attractive for radiological applications. The goal is for materials with enhanced adsorption, impregnation and solidification abilities. The greater ordered geometry will lead to greater efficiency in sorption, and the ability to functionalize will aid in developing a more robust material for the acidic environments of reprocessing (eg,. addition of carboxylate groups).

Nanotubes are shown to be promising for preconcentration and solidification of Ac and La from aqueous solutions. However, the kinetics are very slow. Methods of pretreatment (shown for Th, Am) and/or functionalization will aid in improving the kinetics. (Belloni, Ceren, Rondinella, Carbol, Wiss, \& Mangione, 2009) (Wang, Sato, \& Xing, 2005)

Endohedral fullerenes have been shown to incorporate small quantities of noble metals and lanthanides into their cages. (Saunders, Jimenez-Vazquez, \& Cross, 1994) (Yu, Jin, Liu, Yao, Liu, \& Balch, 2012) Generally they form via the high temperature and pressure vaporization of graphite with gases or metal oxides in very low yields. Potential areas of research in this area could target the following: higher yields and production in bulk quantities and increased mole fraction of noble metals and lanthanides in the cages. Furthermore, it is intriguing to imagine the ability to utilize the endohedral fullerenes for in-situ fuel isotope 'gettering' due to their temperature stability.

Silica Aerogels are high surface area $\left(\sim 1250 \mathrm{~m}^{2} / \mathrm{g}\right)$, high porosity $(\geq 90 \%$, mainly mesopores in the $2-50 \mathrm{~nm}$ range), high thermal stability, noncrystalline materials which are easily prepared by solution condensation, gelation, and supercritical drying). They also exhibit high mechanical and chemical durability. They are inherently hydrophobic and can be tuned by functionalization of the surface with 
metals or organics for gettering applications. However, they do not have size selectivity due to their lack of crystallinity, as compared to the zeolites, MOFs, carbon nanotubes, etc. (Matyas, Fryxell, Busche, Wallace, \& Fifield, 2011) (Katoh)

To avoid the need for functionalization and to build in chemical preference sorption based on "framework" composition, researchers are studying novel chalcogels for the capture of fission gas products. Chalcogels are aerogels made with non-oxide building blocks (eg,. $\mathrm{Ge}_{4} \mathrm{~S}_{10^{4}}$ ) and interlinking metals (eg., $\mathrm{Sn}^{2+}$ ), (Riley, et al., 2011). To date, Ge-S chalcogels have proven to be effective iodine sorbents in streams of both high and low iodine concentration. The potential is there to be able to heat treat the captured gas - chalcogen to directly form a waste form for permanent storage of the fission gas. For example, studies are underway into the tuning of the gel melt to glass with minimized captured iodine gas loss upon heating.

Uranium from Seawater: In an effort to find affordable and plentiful uranium sources worldwide, one need not look further than the efforts to develop nanoparticle and nanoporous materials for the separation of uranium from seawater. (Sodaye, Nisan, Poletiko, Prabhakar, \& Tewari, 2009) Uranium mainly exists in seawater as an anionic species, $\left[\mathrm{UO}_{2}\left(\mathrm{CO}_{3}\right)_{3}\right]^{4-}$ at concentrations of a few parts per billion. The stability of the uranyl carbonate complex and the very low concentration require materials to have high affinity and rapid kinetics to be effective in the recovery of uranium. Both inorganic and mixed organic-inorganic materials are being developed to sorb the uranyl carbonate ion. On the side of inorganic, a variety of materials are being studied and are available for improvement, including hydrous titanium oxide nanopowders (U $660 \mathrm{mg} / \mathrm{g} \mathrm{HTO}$, slow elution), activated carbon (U $500 \mathrm{mg} / \mathrm{g} \mathrm{C}$ ) and Galena (PbS, nanoparticle surface adsorption) (U $1100 \mathrm{mg} / \mathrm{g} \mathrm{PbS}$ ). A molybdenum hydrogen bronze $\left(\mathrm{HMo}_{2} \mathrm{O}_{6}\right)$ oxide material is also being developed for this application, with recorded uranium adsorption from laboratory non-seawater conditions of $5.14 \mathrm{mEq} / \mathrm{g}$. (Apblett, 2010)

The value of the inorganic materials for this application is the ease of production, the ability to make nanoparticulate in size for improvements in kinetics and selectivity, and the large quantities available through commercial sources make them competitive even with their relatively low loading levels.

Mixed organic-inorganic materials for this application include highly tuned nanoporous materials (eg., charged MOF frameworks) in which the framework pore structure and the choice of metal centers for chemisorption and net overall charge, may make significant impacts in this field of uranium extraction from seawater. The inclusion of these materials into polymer organic membranes for easy processing and production will also enhance their importance to this application.

However, the materials with extremely high selectivity and capacity are amidoxime ("A" ligand) polymers, (U $3000 \mathrm{mg} / \mathrm{g} \mathrm{A}$ ) via coordination chemistry. While coordination chemistry is outside the scope of this nanonuclear workshop, the 
incorporation of amidoxime into or onto nanoporous materials for a mixed-matrix nanomaterial is within the scope.

A good example of a multidisciplinary approach to improving on amidoxime and learning from its structure-property relationship for uranyl ion extraction, is the multilab effort being led by ORNL (Felker \& Dai, 2011). A combination of modeling, polymer modification and characterization is focusing on optimization via enhanced chain functionalization and Uranyl extraction. (Vukovic, Watson, Kang, Custelcean, \& Hay, 2012)

Furthermore, more closely to this workshop's focus, ORNL is focusing on nanoporous supports (Ordered Mesoporous Carbons: engineered porous materials with ultrahigh surface areas and tunable pore sizes (no need for branched polymer chains and enhanced stability)) and Multiwalled Carbon Nanotubes (Wang, Liang, Dai, \& Langmuir, 2008) (Liang \& Dai, 2006). Use of nanoporous supports allows for diffusion and adsorption reactions on the nanoscale.

\section{Capability and Facility Needs}

The facilities and equipment described for nanomaterial design and characterization in the previous subsections would be utilized for nanomaterial chemical interaction and separation methods development. Development of these materials will require testing with radioactive materials. Consequently the hot cells and radiological facilities as described in the previous subsections will be required to support the development of these advanced materials.

\section{Recommended Future Research}

Molecular dynamics simulation and Monte Carlo/first principles modeling, critical to design and analysis of structure-property relationship determinations, such as:

○ MD Simulations, gas bonding and adsorption isotherms inside pores

○ $1^{\text {st }}$ Principles: electronic structure of nanoparticles, gas sorption

Stimuli based processes - refers to processes that rely on external stimuli of the nanoparticles and/or nanoporous materials. Examples include magnetic and electrochemical stimuli, whereby the nanomaterial responds to the magnetic or electrochemical field to effect a chemical interaction or separation. Examples include:

- Scintillating nanoparticles for sensing applications

- Magnetic separation using reactive and magnetic properties of nanoparticle

- Electrodeposition on porous alumina supports Nanoclusters/physical separations - The development of strategies of anion separations utilizing shape and charge selectivity can be explored with a variety of nanocluster - like systems, including polyoxometalates (POMS). POMs are nanoparticle/nanoclusters which are polyatomic ions of 3 or more transition metal 
oxyanions linked by oxygen atoms. Reduction of an oxidized POM allows it to accept anionic compounds (eg., pertechnetate, $\mathrm{TcO}_{4}$ ) for removal from solutions. (Nuclear Separation Technologies Workshop Report, Nov 7, 2011).

Other examples of nanocluster separation process methods include:

- Peroxide induced uranium nanoclusters precipitation from solutions

- Metal oxide mineral analog precipitation (Bi-O-I hydrotalcite layered phases for iodide and iodate removal from caustic solutions (Krumhansl \& Nenoff, 2011)

Chemisorbed/Physisorbed materials - refers to those materials that are specifically developed to adsorb target materials either by a chemical interaction with the target material (chemisorption) or by physical adsorption in which the electron structure of the target material is not affected (physisorption). Examples of these materials include the following:

○ Metal organic frameworks, silica aerogels, chalcogels, zeolites, hydrogen bronzes, porous organic solids (polymethyl methacrylates)

Supported systems - refers to the use of nanoporous materials or nanoparticles coupled with conventional substrate materials.

- Nanocomposites (nanoparticles and/or nanoporous materials in polymers to form mixed matrix membranes (Jeazet H. , Tanh, Staudt, \& Janiak, 2012)

- Electron beam grafting of polymers for Cs and U separations

- Porous glass substrates for enhanced stability in harsh environments Sodium titanates (Duff, 2004)

\section{Summary}

The overall conclusion of the Chemical Properties and Separations session of the NanoNuclear Conference is that nanoscience and nanomaterials offer very good potential to impact many aspects of nuclear energy systems and should be a subject for R\&D investment. The most immediate impact would be expected in the area of radiochemical separations by enhancing selectivity and kinetics. It was viewed that even if nanoscience did not necessarily make wholesale changes in the way chemical interactions and separations are carried out in nuclear processes, it could offer equal potential impact in the way the polishing operations are carried out to improve recycled product purity and eliminate product losses. The session concluded that studies should be performed in three focal areas: 1) design and synthesis of nanoporous materials and nanoparticles, 2) characterization of the behavior of nanomaterials, especially after being subjected to the extreme radiation, temperature, and pressure environments associated with the nuclear fuel cycle, and 3) chemical interaction and separations methods development. Several specific research studies have been recommended in each of these focal areas, such as surface passivation, surface functionalization, development of new characterization methods, stimuli-based processes, and uranyl nanoclusters, to name a few. It was 
also noted in the session, that even though five DOE Science centers exist for the study of nanomaterials, none are equipped for the study with radiological materials. Excellent radiological facilities exist throughout the national laboratories and at a number of universitiesin the US. Increased collaborations in the form of greater user access among the DOE Nanomaterial Science Centers and organizations with radiological experience and facilities would accelerate the development of nanomaterials for use in nuclear energy systems. However, user access to these scientific research facilities must be conducted with full cognizance of the safety hazards that are associated with highly dispersible nanomaterials, especially when they are associated with radiological materials.

\section{Mechanical Properties/Structures}

The primary focus of this breakout session was the use of nano-technologies to improve and monitor mechanical and corrosive properties in nuclear reactors. This realm of application potential extends from the most severe environments in the core of the reactor to coolant piping, baffle plates, pressure vessel or the concrete enclosure outside of the reactor.

Among the many potential mechanical improvements that nanoscience may provide the nuclear industry are:

- incorporation of nano-sized precipitates in alloys to improve irradiation tolerance by acting as sinks for radiation-induced defects to improve high temperature strength

- nanostructured coatings or surface treatments for structural steel, reinforcing bar, and concrete support structures to inhibit corrosion

- use of nanolayered strengthened composite materials

- nanoscale sensors and in-service monitors.

These research applications should be strongly coordinated with nanomaterial developments for uses in other parts of the reactor. For example, cladding materials development must be coordinated with nuclear fuels development to avoid issues with materials interactions under irradiation. Also, coating applications for coolant piping must be coordinated with nanomaterial applications for fluids to assure compatibility.

In general, nanomaterials applications to the nuclear industry will require significant testing coordinated with materials development to qualify new materials for service. These efforts would be greatly improved through the development of physics-based models to help realize the benefits of these applications at the nanoscale. Through the development of models that capture processes at the atomic scale, materials can be tailored to the specific nuclear application and eventually these models can be used to predict lifetimes under extreme nuclear reactor environments. 


\section{Structural Applications}

Conditions in the core of a nuclear reactor can vary significantly depending on the design. For example, the neutron flux and energy significantly varies from greater than $10^{15} \mathrm{n} / \mathrm{cm}^{2} / \mathrm{s}$ for a fusion reactor and neutron energies are on the order of 14 $\mathrm{MeV}$ to a similar flux for a fast reactor with energies that are roughly $1 \mathrm{MeV}$. Thermal reactors have a typical neutron flux of $10^{14} \mathrm{n} / \mathrm{cm}^{2} / \mathrm{s}$ with both fast and thermal energy components. Beyond the neutronics, temperatures and pressures vary widely as well ranging from a high of $900-1100^{\circ} \mathrm{C}$ for high temperature gas reactors or some fusion reactor designs to down to $250-350^{\circ} \mathrm{C}$ for a light water cooled thermal reactors. Because of the improved strength up to high temperatures and radiation tolerance, nanomaterials may have numerous uses in reactor applications, that might provide transformational benefits in some cases.

The materials issues for this diverse set of reactor core conditions are accordingly wide ranging.

LWR cladding materials must maintain stability during a loss of coolant accident in an atmosphere of superheated steam reaching temperatures greater than $1200^{\circ} \mathrm{C}$ while still meeting the strict neutronics, reliability and burn-up requirements during normal operation. Cladding materials in fast or fusion reactors must withstand irradiation doses greater than 150-200 dpa at temperatures from 400 to $550^{\circ} \mathrm{C}$, or possibly higher, depending on the design.

LWR internal components such as baffle plates or core supports, although subjected to a lower neutron flux are expected to last for the life of the reactor where they can accumulate doses up to 80-100 dpa embrittlement and resist corrosion and cracking while continuously immersed in water.

The challenges to reactor vessels depend on the reactor type and design, but generally involve appropriate combinations of strength and toughness combined with resistance to irradiation embrittlement and corrosion. Challenges for coolant piping center around corrosion including crevice corrosion, stress corrosion cracking, pitting, intergranular attack and erosion or flow-assisted corrosion. Because of the high operating temperatures in VHTRs, the materials issues encountered by heat exchangers consist of oxidation and high temperature creep.

The materials presently used for these applications have gone through rigorous qualification test campaigns and their compositions have been optimized for their applications. For example, for cladding applications zirconium based alloys are used for LWRs, austenitic or ferritic/martensitic alloys for sodium-cooled fast reactors and $\mathrm{SiC}$ coatings are used in the Very High Temperature reactor (VHTR). For core internals, austenitic iron and nickel based alloys are generally the material of choice for LWR's and fast reactors while higher temperature materials such as SiC composites or Alloy $800 \mathrm{H}$ are used for the VHTR. The materials for heat exchangers 
in LWR's are Inconel alloys such as 600 or 690, austenitic or ferritic/martensitic steels for the SFR while Alloy 617 is used in the VHTR. To replace these materials with nanomaterials the present advantageous properties must be matched while providing an improvement in properties from the nano-structured materials.

\section{Application of Nano-Technologies}

\section{LWR Cladding}

One of the potentially most beneficial applications of nanotechnology is for improving the corrosion/oxidation resistance and high temperature strength of LWR cladding materials in an accident scenario. Candidate methods for doing this are the following:

\section{Nanoferritic alloys (NFA) with aluminum additions}

These alloys (examples are PM2000 and MA-956) consist of a ferritic matrix with chrome additions of 16 to $20 \mathrm{wt} . \%$ and aluminum content of $~ 5 \%$. Currently these have yttria-aluminum precipitates with an average size $>\sim 5 \mathrm{~nm}$. The precipitates provide modest improvements in high temperature strength and may serve as sinks for irradiation-induced defects. The high aluminum and chrome content provide excellent oxidation resistance in steam to temperatures up to $1300^{\circ} \mathrm{C}$. Because of the high thermal neutron cross section of these alloys compared to zirconium alloys, the wall-thickness would need to be reduced or the fuel enrichment increased for use these alloys in LWRs. Improved strength could be an advantage and might be achieved by composition modifications [Kimura, 2011]. One of the disadvantages of using these alloys is that they are presently produced with powder metallurgical processing paths which are costly. Further, because of their high strength, they are more difficult to process into tubing or other complex parts and conventional joining techniques can't be used with these alloys because they may destroy the fine scale oxide dispersions. So, advanced techniques such as friction stir welding must be developed for joining these alloys.

\section{NITE-SiC and SiC and $\mathrm{Si}_{3} \mathrm{~N}_{4}$ with nanodiamond}

These ceramic composites can provide excellent high temperature strength and oxidation resistance and provide a similar thermal neutron cross section to that of zirconium alloys. One of the main drawbacks of these alloys are their low fracture toughness and joining difficulties. Thus, research is needed to develop improved brazing or other joining techniques that are robust under reactor operating conditions (E.D. Herderick, 2012) (H. Kishimoto, 2011). Thus nano-dispersion strengthened brazes may present some opportunities. 


\section{Fast Reactor Cladding}

Nanoferritic Alloys (NFAs)

These alloys consist of ferritic or ferritic/martensitic alloys with 9-14 wt.\% chrome and titanium and yttrium added to form yttrium-titanium (mixed) oxide dispersions [Odette, 2008; Odette, 2010]. These 2-4 nm diameter dispersoids ideally are uniformly distributed in the ferritic matrix and provide excellent high temperature strength and superb irradiation tolerance [Odette, 2008; Odette, 2010] (See Fig. 1 a and $b$ ). As noted above, one of the disadvantages of these alloys is that they are produced currently with time-intensive, solid state powder metallurgical processes resulting in high costs and contamination, where joining is also a key issue.

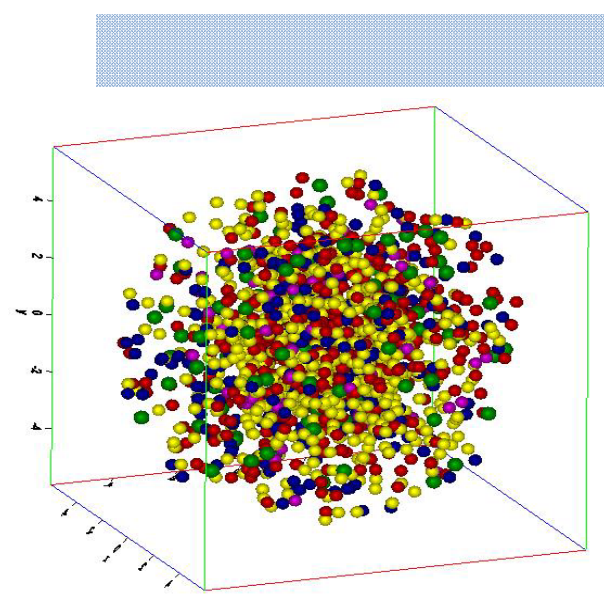

Fig 1. Schematic showing advantages of nanofeatures (b) providing sinks for radiation defects and He atoms while also improving high temperature strength from Odette 2008.

Advanced Ferritic Alloys with a thermomechanical treatment to produce a nanoscale dispersion

These alloys consist of 9-12 wt \%Cr ferritic alloys with a fine distribution of nitride or carbide precipitates uniformly dispersed through the alloy (Klueh, 2007) Through thermo-mechanical treatment, a uniform grain structure is produced with a much finer dispersion of precipitates with sizes ranging from 3-150 nm improving the strength and radiation tolerance. These alloys can be produced using conventional melt processing techniques. The stability of the precipitates needs to be investigated under long term irradiation and at high temperatures.

\section{Nano and Micro Layered Composites}

These alloys consist of fine nm-thick multilayers of pure materials that are immiscible. One model alloy under investigation is $\mathrm{Cu} / \mathrm{Nb}$. The high density of interfaces serves as excellent sinks for irradiation induced defects and provide increased strength (Misra, Demkowicz, Zhang, \& Hoagland, 2010) [see Figure 2]. 
Recently bulk $\left(>\mathrm{cm}^{3}\right)$ laminar composites with controllable layer thicknesses down to the submicron or nano-scale range have been fabricated via accumulative roll bonding (ARB), a severe plastic deformation (SPD) processing technique (See Figure 2). (Carpenter, Vogel, LeDonne, Hammon, \& Beyerlein, 2012). The ARB process itself is an extreme condition imposing over thousands of percent strain, refining the microstructure of ordinary coarse-grained composite metals down to submicron and nanoscales. ARB is an ideal model material processing technique for three reasons: 1) it produces a 2-D layered microstructure, 2) it imposes monotonic deformation in a familiar manner (rolling), and 3) it allows for controllable accumulated strain and layer thickness (from $1 \mathrm{~mm}$ to $10 \mathrm{~nm}$ ). However, the bimetal interface parameter space and number of possible synthesis pathways are prohibitively large for effective experimental investigation. Current research focuses on manipulating the ARB process to achieve desired interface properties by way of developing a multi-scale predictive model that forecasts the evolution of interfacial properties $(\mathrm{nm})$ during the bulk forming process $(>\mathrm{cm})$. An example of such a property (strength), as well as elevated temperature stability found in this class of materials, even after annealing at very high temperatures $\left(700^{\circ} \mathrm{C}\right.$ for 1 hour), can be seen in Figure 3, where nanohardness measurements reveal two orders of magnitude improvement in strength over the bulk constituents.

Clearly, many challenges, including joining and manufacture of specific industry-relevant material systems, still exist for placing this technology into reactor applications, However, with the fundamental knowledge of which specific interface types that can deliver enhanced properties evolve during thermomechanical processing ,engineered alloys based on $\mathrm{Fe}, \mathrm{Zr}$, Al, etc., can be designed.

Laminated metal-metal and metal-ceramic composite structures at larger length scales do not provide enhanced irradiation tolerance from the perspective of defects per-se, but can enhance mechanical properties relative to individual constituent behavior. For example ductile phase toughening could enable the use of matrix constituents that are intrinsically brittle, or embrittled by radiation damage. Nano material approaches can then be used to improve the properties of the constituents.

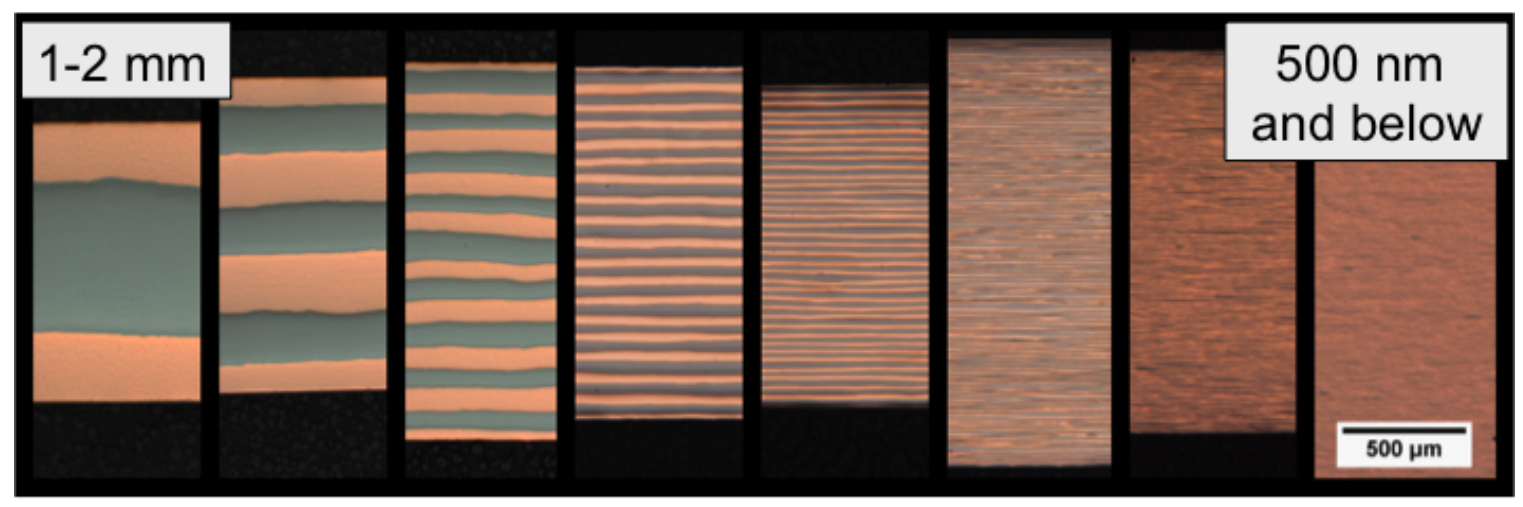

Figure 2: Optical micrographs of Bulk $\mathrm{Cu}-\mathrm{Nb}$ multilayers produced via Accumulative Roll Bonding. Starting layer thicknesses are on the order of millimeters, and the 
layer thicknesses can be refined down to 10 nanometers while retaining bulk sample dimensions and a continuous layered structure.

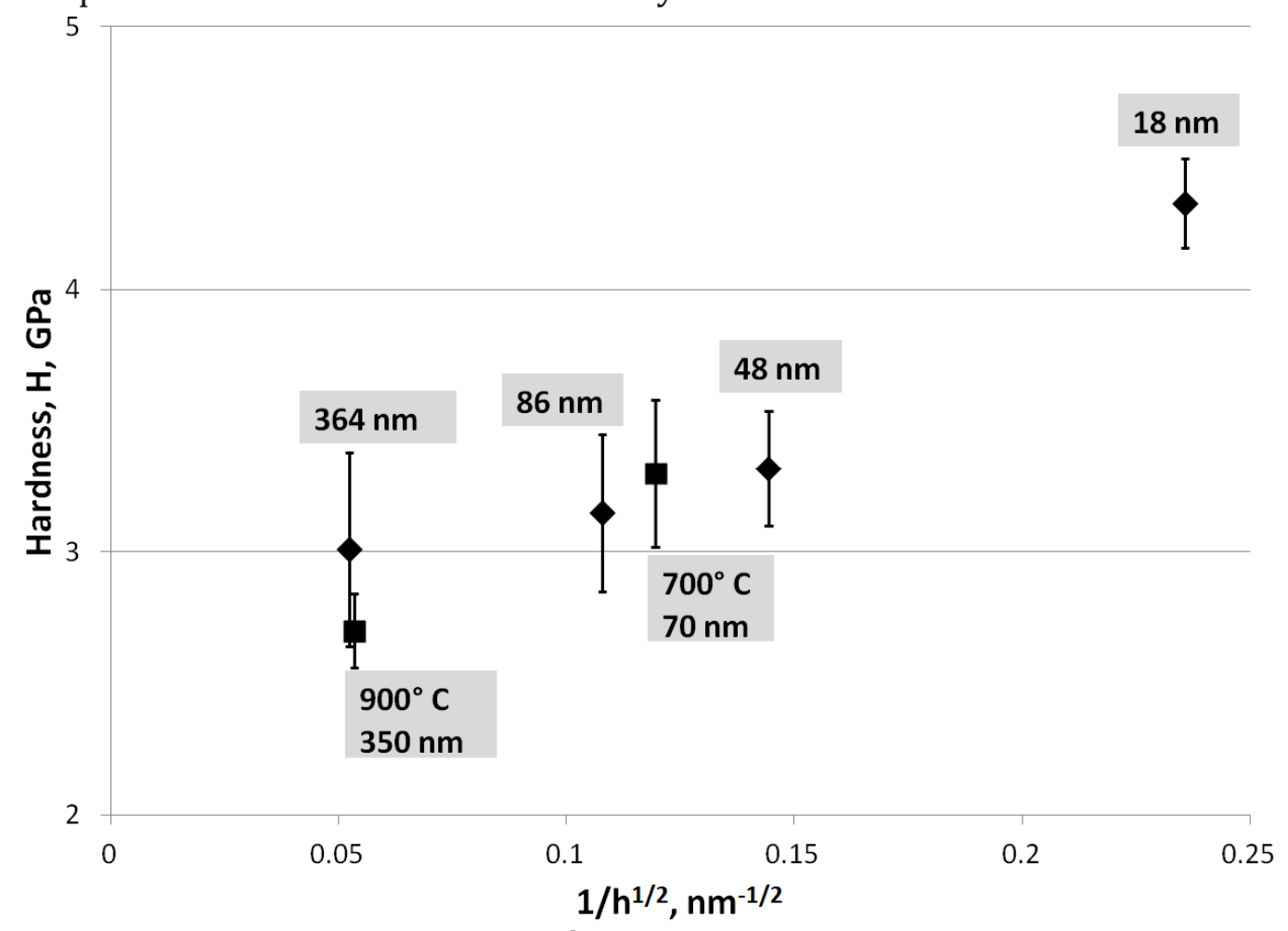

Figure 3: Plot of Hardness vs. 1/ layer thickness for ARB processed $\mathrm{Cu}-\mathrm{Nb}$ bulk material. In this case, hardnesses can approach those of tool steel, despite being comprised of two relatively soft metals. As shown, the square data points (annealed material) fall into the trend of the unannealed material, despite having been heated to over $70 \%$ of the melting point of copper.

\section{Heat Exchangers for VHTRs}

Very High Temperature Gas Cooled Reactor steam generators are among the components of a nuclear plant subject to the most demanding extremes of temperature differentials, pressure differentials and mechanical stress (vibration) with little to no neutron exposure. Nanomaterials that may be suitable for this application are metal alloys with 5-200 nm diameter nano-carbon added to it.

\section{Coolant Piping for VHTRs}

Coolant piping for the Very High Temperature reactor requires the development of materials that have excellent high temperature strength and creep properties. The present material of choice is Alloy $800 \mathrm{H}$. As noted above, NFAs can provide excellent high temperature strength and may be a superior alternative. 


\section{Capability and Facility Needs}

Facilities to perform high dose irradiation tests

Large-scale production facilities for nanomaterials

Facilities for performing high temperature testing including in steam for the development of improved accident tolerant cladding materials.

\section{Recommended Future Research}

Development of nano-strengthened ferritic and nickel based alloys and high performance composites incorporating nanomaterials technologies Development of joining techniques that preserve the benefits of nanoscale components.

Development of scalable fabrication techniques for nanomaterials to reduce cost

\section{Coatings and Barriers}

Many of the structural challenges previously described may be better addressed through application of coatings or barriers rather than replacement of the complete component with these materials. For example, resistance to corrosion may be easier and more cost effectively achieved by coating the interior or exterior surfaces of a component with a nanomaterial than by fabricating the component out of a more exotic material.

\section{Application of Nano-Technologies}

\section{Fuel Cladding for LWRs and Fast Reactors}

A key challenge for both LWRs and Fast Reactors is reduction of fuel cladding chemical interaction (FCCI). This issue is most aggravated in metallic fuels for fast reactors because the higher operating temperatures (above $600^{\circ} \mathrm{C}$ ) and greater than $10 \%$ burnup causes the steel cladding to interact with the metallic fuel. Present research is investigating TiN or pure $\mathrm{Zr}$ as a barrier to $\mathrm{FCCI}$ but a possible nanomaterial application to reduce FCCI could be coating the fuel meat with functionally graded carbon nanotubes. Radiation tolerance of this coating would have to be determined.

LWR cladding materials may also be similarly enhanced by nano-enabled strategies such as coatings. Grid to rod fretting, one of the leading causes of cladding failures, might be mitigated by thermal spraying a thin ceramic carbide or nitride coating or by application of a bulk metallic glass with a high transition temperature. One advantage of using coatings rather than replacing the cladding material is that the use of materials with a high thermal neutron cross-section is less of an issue because of the small volume of material required. 
A third possible application of coating materials to cladding is to improve the cladding's performance in an accident scenario. Coatings can be envisioned that greatly improve the resistance to high temperature oxidation in steam and possibly improve the stability through maintaining cladding integrity during LOCA conditions. Examples include $\mathrm{FeCrAl}(\mathrm{Y})$ coatings that have been developed as part of (bond and oxidation coats) thermal barriers for aerospace applications. Nanodispersion strengthening of these alloys would lead to improved performance. In this application, it would be important to keep the coating as thin as possible to allow for heat removal by the coolant and to tailor the thermal expansion to match that of Zircaloy to prevent cracking during the high temperature excursion.

\section{Coolant Piping Applications}

Improving the corrosion resistance of LWR coolant piping can be addressed through multiple avenues. One possibility is to add nanometer grained powders (e.g. Pt) to the coolant that plate out on the piping to prevent corrosion or stress corrosion cracking issues. Other potentially applicable methods are electrodeposition or vapor deposition techniques to deposit nickel alloys to repair steam generator tubing replacing the need for welding or full replacement. A third application is to coat the inside of piping with nanomaterials such as graphene which could provide a protective layer to prevent or reduce corrosion issues. Graphene can be deposited on a polymer which is dissolved to be applied on the surface of metals.

\section{Capability and Facility Needs}

Capabilities to measure coating thickness before and after irradiation

\section{Recommended Future Research}

Develop coating techniques for applying nanomaterials to cladding tubes or coolant piping

Perform corrosion tests on coatings under prototypic reactor conditions

Perform irradiation tests on coatings to assure their integrity under irradiation Perform thermal cycling tests on coatings

\section{Nano-layered/Strengthened Composite/Hybrid Materials}

\section{Concrete}

Nanomaterials could provide significant improvement to concrete structures for application in the nuclear industry. Nanomaterials, including fly ash particulate, 
added as powders to concrete can possibly improve strength and toughness. Examples include the addition of graphene oxide or boron nitride nanotubes to concrete. Research is needed to optimize the benefits but this could lead to reduced issues with concrete cracking.

\section{Heat exchangers}

Nanomaterials in composite form can provide increased strength and excellent thermal conductivity which is ideal for heat exchanger applications. Examples include boron-nitride nanotube reinforced fabrics.

\section{Capability and Facility Needs}

Same as discussed above

\section{Recommended Future Research}

Test mechanical properties of concrete reinforced with nanomaterials

Develop techniques for producing heat exchangers using BN-NT reinforced fabrics. Test thermal performance of these composite materials.

\section{Sensors and In-service Monitors}

Because of the extremely small size of nanomaterials, their application to in situ monitors for nuclear applications is ideal. With a minor perturbation to the reactor, one may be able to monitor temperature, corrosion, neutron flux, stress/strain or even chemistry. This could have significant benefits because in many cases, these measurements are not able to be performed because of the extreme reactor conditions. This results in operating the reactor with increased safety margins.

In addition, because nanomaterials tend to have uniform properties down the nanoscale, microscale testing techniques that show significant variations in properties when applied to common engineering materials, show excellent reproducibility when performed on nano-structured materials.

\section{In-Core Reactor Applications}

The most challenging environment for performing in situ measurements is in the core of the reactor. Sensors in this environment must be able to withstand very high neutron fluxes, temperatures from 250 to $>1000^{\circ} \mathrm{C}$, and contact with flowing coolant ranging from water to liquid metal to helium. While measurements in this 
environment are very challenging, such data would be very valuable to the nuclear industry.

Optical fibers made of alumina with Pt/Pt-Rh thermocouples with a 10 micron diameter may be capable of providing temperature measurements under these extreme conditions. A 10-20 micron four point probe made of platinum may be capable of serving as a corrosion monitor. Micron-sized monitors or MEMS sensors for stress/strain have been developed that may be able to be used for in situ measurements. Chemistry (such as hydrogen) can be monitored in the coolant using micron down to nano-sized Pd or W sensors. These sensors are produced using direct write (printing) microfab technologies. The radiation tolerance of these sensors needs to be assessed to determine their lifetime in a nuclear environment.

\section{Coolant Piping}

Assessing and monitoring corrosion in coolant piping is essential to the operation of nuclear reactors. Micron-sized sensors may allow one to monitor in locations that are very difficult to access or reduce the size of sensors presently being used. As noted above 10-20 micron four point probes may be able to be used on coolant piping along with micron-sized strain monitors.

\section{Concrete Monitoring}

Long term monitoring of concrete for the life of the reactor may have many benefits. For this application the environment is not as extreme as that in the core of the reactor but the sensor must be able to last for decades. Examples of monitors could be micron sized stress/strain monitors or electrical conductivity or ultrasonic measurements.

\section{Surveillance Monitoring}

Reactors often use surveillance specimens to monitor changes in mechanical properties. These coupons can be cut from larger components if a failure occurs or are inserted as small coupons. With the development of micron-sized mechanical testing through cutting samples with a focused-ion-beam, surveillance testing can be performed on micron-sized specimens. This greatly reduces the size of the specimen required for performing surveillance testing resulting in reduced dose to the worker and reducing the sample size that must be retrieved from the reactor location. Such testing may be ideal when used for testing nanomaterials because of these materials typically have uniform properties on the micron-scale. 


\section{Capability and Facility Needs}

Sensor test facilities under typical water coolants and radiation environments.

\section{Recommended Future Research}

Develop and test sensors under prototypic reactor operating conditions. Determine their lifetime under irradiation

\section{Summary}

This breakout session was primarily focused on nanomaterial applications to structural materials and sensors and surveillance monitoring. Overall, it was noted that coupling physics-based modeling with the development of nanomaterials for nuclear applications will aid in materials selection and the eventual development of models to predict changes in materials properties in a nuclear environment. Structural applications ranged from cladding development for improved Accident Tolerant Fuels to coolant piping or concrete applications. Nanomaterials for structural applications ranged from nano-strengthened ferritic alloys (NFAs) to nano-strengthened ceramic composites or concrete strengthened with carbon nanotubes. Applications to structural materials could also be accomplished with nanomaterials in the form of coatings or nano-layered composites. In situ measurement of property changes could be accomplished using micron-sized sensors and surveillance testing can be performed using micron-scale mechanical testing techniques. 


\section{References}

A. Kimura, R. K. (2011). Journal of Nuclear Materials. 417, 176-179.

Apblett, A. (2010). ACS Symposium Series , 1046, 155.

Armstrong, C., Nyman, M., Shvareva, T., Sigmon, G., Burns, P., \& Navrotsky. (2012).

Proceedings of the National Academy of Science.

Bell, N., Liu, H., Garino, T., Rodriguez, M., Rademacher, D., \& Nenoff, T. (2012). Novel

Ceramic Nanofiber Membranes as Nuclear Wast Separation and Sequestration Scaffolds.

Waste Forms for Environmental Remediation Symposium, ACS Spring National Meeting,

San Diego, CA .

Belloni, F., Ceren, K., Rondinella, V., Carbol, P., Wiss, T., \& Mangione, A. (2009).

Environmental Science Technology, 43 (5), 1250-1255.

Buonginorno, J., Venerus, D., Prabhat, N., \& McKrell, T. (2009). A Benchmark Study on the Thermal Conductivity of Nanofluids. Journal of Applied Physics , 106.

Buongiorno, J. (2006). Convective Transport in Nanofluids. Journal of Heat Transfer, American Society of Mechanical Engineers , 128 (3), 240.

Buongiorno, J., Hu, L., S., K., Hannink, R., Bao, T., \& Forrest, E. (2008). Nanofluids for Enhanced Economics and Safety of Nuclear Reactors; An Evaluation of the Potential Features, Issues, and Research Gaps. Nuclear Technology, 162 (1), 80-91.

Burns, P., Ewing, R., \& Nayrotsky, A. (2012). A, Science, 335, 1184-1188.

Carpenter, S., Vogel, J., LeDonne, D., Hammon, I., \& Beyerlein, N. M. (2012). Acta

Materialla. 60 (4), 1576.

Chapman, K., Chupas, P., \& Nenoff, T. (2012). Radioactive Iodine Capture in Silver-

Loaded Zeolites Through Nanoscale Silver Iodide Formation. Journal of Americal

Chemical Society, 132 (26), 8897-8899.

Chapman, K., Sava, D., Halder, G., Chupas, P., \& Nenoff, T. (2011). Journal of

American Chemical Society, 133 (46), 18583-18585.

Duff. (2004). Environmental Science Technology, 38 (19), 5201-5207.

E.D. Herderick, K. C. (2012). Advanced Materials \& Processes.

Eddaoudi, M., Kim J, Rosi N, D., V., wachter, J., O'Keeffe, M., et al. (2002). Science , 295, 469-472.

Felker, K., \& Dai, S. (2011). ANS Meeting. ORNL, LBNL, UTA.

Fernandez, C., Liu, J., Thallapally, P., \& Strachan, D. (2012). Journal of American Chemical Society, 134 (22), 9046-9049.

H. Kishimoto, T. S. (2011). IOP, Diffustion Bonding Technology of Tungsten and $\mathrm{SiC} / \mathrm{SiC}$ Composites for Nuclear Applications. 3rd International Congress on Ceramics . Jeazet, H., Tanh, H., Staudt, C., \& Janiak, C. (2012). Chemical Communication , 48, 2140-2142.

Jeazet, H., Tanh, H., Staudt, C., \& Janiak, C. (2012). Chemical Communication , 48, 2140-2142.

Kalantar-Zadeh, K., \& Fry, B. (2007). Nanotechnology enabled sensors. New York.

Katoh, Y. Ceramic Engineering and Science Proceedings. 32 (9), 23-33.

Kim, H. (2011). Enhancement of Critical Heat Flux in Nucleate Boiling of Nanofluids: A State-of-Art Review. 6 (1), 415.

Kim, H., Buongiorno, J., L.W., H., \& T., M. (2010). Nanoparticle Deposition Effects on the Minimum HEat Flux Point and Quench Front Speed During Quenching in WaterBased Alumina Nanofluids. International Journal of Heat and Mass Transfer , 53, 7-8. 
Kim, S., Bang, I., Buongiorno, J., \& L.W., H. (2007). Surface Wettability Change During Pool Boiling of Nanofluids and it's Effect on Critical Heat Flux. International Journal of Heat and Mass Transfer , 50, 19-20.

Kim, S., McKrell, T., Buongiorno, J., \& L.W., H. (2009). Enhancement of Flow Boiling Chritical Heat Flux (CHF) in Alumina/Water Nanofluids. Advanced Science Letters , 2 , 100.

Klueh, R. e. (2007). Journal of Nuclear Material , 48, 367-370.

Krumhans1, J., \& Nenoff, T. (2011). Applied Geochemistry , 26 (1), 57-64.

Leung, K. (2012). Journal of Chemical Physics , 137 (7).

Liang, C., \& Dai, S. (2006). Journal of American Chemical Society. 128, 5316-5317. Matyas, J., Fryxell, G., Busche, B., Wallace, K., \& Fifield, L. (2011). Functionalized Silica Aerogels: Advanced Materials to Capture and Immobilize Radioactive Iodine. Chapter 3 in Ceramic Materials for Energy Applications: Papers from the American Ceramic Society's 35th International Conference on Advanced Ceramics and Composites. MC, D., DB, H., DT, H., SD, F., Z, D., \& JP, B. (2004). Mechanisms of Strontium and Uranium Removal from High-Level Radioactive Waste Simulant Solutions by the Sorbent Monosodium Titanate. Environ Sci Technol , 38 (19), 5201-5207.

Misra, A., Demkowicz, M., Zhang, X., \& Hoagland, R. (2010). The radiation damage tolerance of ultra-higg strength nanolayered composites. Journal of Materials , 62 (84). Nenoff, T., Jacobs, B., Robinson, D., P.P., P., Huang, J., Ferreira, S., et al. (2011). Chemical Mater.

Odette, G., Alinger, M., \& Wirth, B. (2008). Recent Developments in Radiation Tolerante Alloys.

O'Hanley, H. (2012). Seperate Effects of Surface Roughness, Wettability and Porosity on Boiling Heat Transfer and Critical Heat Flux and Optimization of Boiling Surfaces.

Thesis, MIT.

Riley, B., Chun, J., Ryan, J., Matyas, J., Li, X., Matson, D., et al. (2011). RSC Advances , 1, 1704-1715.

Saunders, M., Jimenez-Vazquez, H., \& Cross, R. J. (1994). Journal of American Chemical Society, 116, 2193-2194.

Sava, D. R., Chapman, K., Chaups, P., J.A., G., Crozer, P., \& Nenoff, T. (2011). Journal of American Chemical Society, 133 (23), 12398-12401.

Si, R., Dr., Y.-W. Z., Prof., L.-P. Y., \& Dr., C.-H. Y. (2005). Rare-Earth Oxide Nanopolyhedra, Nanoplates, and Nanodisks. Angewandte Chemie International Edition, 44 (21), 3256-3260.

Sodaye, H., Nisan, S., Poletiko, C., Prabhakar, S., \& Tewari, P. (2009). Desalination , 235, 9-32.

Spino, J., Santa Cruz, H., Jovani-Abril, R., Britcher, R., \& Ferrero, C. (2012). Bulk nanocrystalline oxide nuclear fuels- An innovative option for increasing fission gas retention, plasticity and radiation tollerance. Journal of Nuclear Materials , 422 (1), 2744.

Thallapally, P., Grate, J., \& Motkuri, R. (2012). Chem. Comm. 48 (3), 347-349. Vukovic, S., Watson, L., Kang, S., Custelcean, R., \& Hay, B. (2012). Inorganic Chemistry, 51, 3855-3859.

Wang, X., Liang, C., Dai, S., \& Langmuir. (2008). Journal of American Chemistry Society. 24, 7500-7505. 
Wang, X., Sato, T., \& Xing, B. (2005). Environmental Science Technology, 38 (8), 2857-8718.

Yu, M., Jin, H., Liu, Z., Yao, M., Liu, B. O., \& Balch, A. (2012). Journal of American Chemical Society, 134 (11), 5331-5338. 